RESEARCH IN INFORMATION SYSTEMS:

INTRA-DISCIPLINARY AND INTER-DISCIPLINARY APPROACHES

FORTHCOMING IN JOURNAL OF THE AIS, APRIL 2018

ACCEPTED JULY 2017

MONIDEEPA TARAFDAR

LANCASTER UNIVERSITY (MANAGEMENT SCHOOL), UNITED KINGDOM

MTARAFDAR@LANCASTER.AC.UK

ROBERT M.DAVISON

CITY UNIVERSITY OF HONG KONG

ISROBERT@CITYU.EDU.HK 


\title{
RESEARCH IN INFORMATION SYSTEMS: \\ INTRA-DISCIPLINARY AND INTER-DISCIPLINARY APPROACHES
}

\begin{abstract}
The deep embeddedness of Information Systems (IS) in many areas of human activity poses a dual challenge to the IS discipline: advancing an expanding disciplinary boundary that includes an increasing set of IS topics; and engaging with other disciplines in order to understand IS-enabled phenomena. An inability to meet these challenges could lead to conceptually stunted development of the IS discipline, missed opportunities to inform other disciplines and a failure to effectively contribute to solving the pressing problems of our time. We undertook this study to investigate both how IS research has addressed these challenges in the past and how it can continue to do so in the future. Drawing on the concept of knowledge-materialization through knowledge-creating practice, and based on approaches for disciplinary and interdisciplinary knowledge creation, we theorize four different types of knowledge contribution that IS researchers can produce, encompassing both an intra-disciplinary and an inter-disciplinary view. We then analyse a wide-ranging sample of research studies published in 176 papers in the AIS basket of eight journals to investigate the nature of their contribution vis-à-vis these types. We find that the predominant types of knowledge contribution are intra-disciplinary, with relatively few inter-disciplinary contributions. Based on our analysis, we explain why each type of knowledge contribution is important to the IS discipline and provide practical guidance for IS scholars in planning their research strategies for these contributions. We comment on the implications of our study for IS scholars and for the vigour and growth of the IS discipline.
\end{abstract}

Key words: IS Discipline, Inter-disciplinary, Intra-disciplinary, Research, Innovation 


\section{INTRODUCTION AND MOTIVATION}

Many academic disciplines are grappling with high levels of IS embeddedness in the phenomena they study, e.g., high speed algorithmic trading and blockchain in Finance, technology induced stress and addiction in Psychology, technology-mediated markets in Economics, and IS-enabled supply chains in Operations Management. Furthermore, journals from other disciplines are devoting particular departments to the study of these IS-specific topics. For example, Product and Operations Management has a department on e-commerce, focusing on the 'synergy between operations and web-based information technology'. Equally, the IS discipline faces challenges associated with studying many different kinds of IS-enabled phenomena. Accordingly, a number of recent special

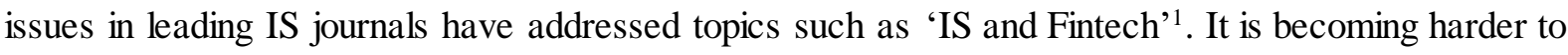
demarcate which phenomena are and are not 'IS-enabled'. Furthermore, IS play an essential role in the solutions to difficult societal problems and challenges spanning multiple disciplines, such as sustainability and border protection. The European Research Council's 'EU Societal Challenges'2 funding program, for example, calls for proposals that demonstrate how IS can 'enable new digital social innovation which can better cope with emerging sustainability challenges'.

These conditions create two challenges for the IS discipline. The first is that of developing, nurturing and advancing a constantly expanding disciplinary boundary that includes an everincreasing set of IS topics and IS phenomena. The second is of engaging with other disciplines to understand IS-enabled phenomena and develop solutions to complex societal and organizational problems. An inability to meet these challenges could lead to insular and conceptually stunted development of the IS discipline, missed opportunities to inform other disciplines, and a failure to contribute to the solving of the critical issues of our time. We undertook the research described in this article in order to investigate the question: How has IS research addressed these challenges and how can it do so in the future?

The literature provides a few different perspectives regarding how IS researchers can develop the discipline and engage with researchers from other disciplines. One suggests that IS researchers

\footnotetext{
${ }^{1} \mathrm{http}: / /$ www.jmis-web.org/cfps/JMIS SI Fintech.pdf

2 https://ec.europa.eu/programmes/horizon2020/h2020-sections
} 
should study problems that are proximate to the IT artefact and thus focus on a core and relatively contained set of topics that should define and strengthen the conceptual boundary of the discipline (Benbasat and Weber 1996, Benbasat and Zmud 2003). Another suggests a more pluralistic approach that promotes the study of a diversity of topics both proximal and distal to the IT artefact, and that focuses on the technical and social processes associated with the design, management and use of IS (Robey 1996; DeSanctis 2003, Robey 2003, Agarwal and Lucas 2005, Bryant 2008). A third perspective suggests that IS researchers should not only draw from other disciplines, such as Psychology and Computer Science, in addressing IS research questions, but also conceptually inform these disciplines (Baskerville and Myers 2003, Nambisan 2003).

These diverse perspectives collectively suggest that IS researchers should create knowledge that is both specific and internal to the IS discipline, at the same time seeking to enlighten other disciplines. However, there is little indication as to what extent these forms of knowledge are being created in IS research. Even more importantly, there is little guidance regarding how IS researchers can strengthen and perpetuate the disciplinary identity of IS, while simultaneously informing other disciplines.

This paper has three objectives. The first is to develop a conceptualization of IS scholarship that offers both an intra-disciplinary and an inter-disciplinary view, thereby providing a framework for understanding how the IS discipline can evolve within and in interaction with other disciplines. The second is to investigate to what extent this conceptualization finds expression in current IS research. The third is to provide guidance for IS scholars to implement the conceptualized scholarship.

The paper is structured as follows. We first provide conceptual background for the evolution of disciplines. We then review approaches for paradigmatic (e.g. Kuhn 1970), disciplinary, and interdisciplinary knowledge creation (e.g. Abbott 2001), to theorize four different types of knowledge contributions that IS research can produce. We then conduct an analysis of the nature of contribution, vis-à-vis these types, of a corpus of 176 articles, drawn from the basket of eight AIS journals over the period 2010-2014. From our analysis we describe and qualify each type and explain how it can create particular pathways of development for the IS discipline, bearing in mind our research objective, that 
is, to investigate what extent the IS discipline can meet the twin challenges of developing the IS discipline even as we contribute to other disciplines. We end with a discussion of the contributions and implications of our framework.

\section{EVOLUTION OF DISCIPLINES}

In this section we first examine the idea of the evolution of disciplines drawing on the idea of knowledge-materialization through knowledge-creating practice. We then describe how such evolution takes place, through intra-disciplinary and inter-disciplinary approaches for knowledge creation (e.g. Kuhn 1970, Abbott 2001).

A discipline is a field of study or a body of knowledge that is the object of scholarly attention. The Organization for Economic Cooperation and Development (OECD) defines a discipline as the 'tools, methods, procedures, exempla, concepts, theories that account coherently for a set of objects or subjects' (Strober 2010, p.13). A discipline thus embodies a set of knowledge distinctions and research practices used by academics to formulate and address specific problems (Abbott 2001). A discipline typically: has a departmental structure and status in universities; provides a basis for scholarly training, identity and a job market for new doctorates, and; may be an area of application in practice. It also constitutes a basis for organizing academic careers, hiring scholars to teach and research, and forming specializations at undergraduate and/or postgraduate levels. The disciplinary structure autopoietically perpetuates itself by facilitating the training and certification of future discipline professionals and seeking new scholars primarily from its own discipline, but also from cognate and allied disciplines (Abbott 1998, 2001). In this way disciplines gain and maintain legitimacy over time.

We define the IS discipline as that which studies the human, social and technological phenomena associated with the design, construction, implementation and use of computer-based information systems by individuals, organizations and societies. This definition is drawn from texts and writings that describe topics important to understanding how IS are designed, applied and used, and provide impacts to individuals and collectives (e.g. Orlikowski and Iacono 2001, Benbasat and Zmud 2003, Galliers 2003, Robey 2003, Laudon and Laudon 2014). 
Considered ontologically, disciplines are not static in the domain of their investigation or in the topics they study. They can be conceived of as being in a state of constant flux and boundary shaping. The configuration and reconfiguration of a disciplinary boundary happens through practices of intra- and inter-disciplinary engagement that shape the 'world' that the discipline wants to describe, understand, explain and participate in. A particular discipline engages with this world in order to materialize it in the form of the discipline's knowledge base, undergoes critical examination and reexamination about what constitutes it, delineates its dynamic relationality with different 'worlds' signified by other disciplines, and continually creates and recreates itself (Kuhn 1970). Disciplines engage internally within themselves and externally with one another, to internally and mutually, discursively and iteratively, produce disciplinary knowledge and disciplinary boundaries. This is particularly true of disciplines in the social sciences which tend to lie at the interstitialities between 'knowledge and action, facts and values' (Abbott 2001, p. 8). Disciplinary boundaries, thus, do not have sharp edges. A particular discipline has many topics of study. Over time, the set of topics evolves, with some topics becoming obsolete, some continuing, and others emerging.

\subsection{Intra Disciplinary Practices for Disciplinary Evolution}

New topics of research continually emerge in disciplines. This could happen for a number of reasons, such as: a particular research topic reaches its conceptual limits and is supplanted or complemented by a new, related topic; or, unconventional ideas find voice to challenge mainstream ideas; or, politically important topics are taken up (Abbott 2001). Two key forms of emergence of new topics within a discipline involve the processes of 'differentiation' and of creating 'fractals' (Abbott 2001, p.23). In the first, scholars in a particular topic dig deeper into a particular topic, differentiating its sub-topics with greater and greater specificity and focus in order to understand details and to tackle its complexity. An example of this can be found in technology acceptance studies in IS. Initially, studies examined key determinants of intention to use a system such as its perceived usefulness and perceived ease of use (e.g. Davis 1989). Subsequent studies undertook a deeper examination of each of these concepts, and revealed their antecedents such as particular design elements, their relationships to other concepts such as actual use behaviour, and mediators and moderators of these relationships such as 
organizational norms and expectations. These developments lead to the investigation of still newer sub-topics and the development of revised models (Venkatesh et al. 2003). The second way involves splitting a given topic repeatedly and recursively into the same categories, and investigating the resulting sub-topics in the repeated categories. For example, system implementation at an overall level was first studied in terms of technical, social and managerial aspects (e.g. Markus 1983, Laudon and Laudon 2014). Subsequently, implementation of different kinds of systems/applications such as decision support systems and ERP were individually studied in terms of their respective technical, social and managerial aspects, such that different technical, social and managerial factors specific to each type of application were revealed. As a result of these two mechanisms of differentiation and fractals, disciplines become imbued with different topics as they evolve.

In the IS discipline, the issue of multiple and multiplying topics has been examined in terms of if and how core elements can be defined, around which IS researchers can focus their efforts. For instance, some scholars argue that topics immediate to the planning, design and use of IT artefacts should be studied and that these should form the core of the IS research space around which clear boundaries and paradigms can be established for the IS discipline (e.g. Benbasat and Weber 1996, Benbasat and Zmud 2003, Somers 2009). Other scholars offer a more pluralistic approach, suggesting that IS researchers should examine a diversity of topics relating to the social, societal and human aspects of the design and use of IS, and allow for a dynamic rather than a static core that pragmatically adapts to changing technologies, and their user populations and requirements (DeSanctis 2003, Galliers 2003, Robey 2003, Agarwal and Lucas 2005, Bryant 2008, Clarke 2015). Recent studies for example highlight the opportunity and need for studying IS phenomenon that are emerging from the large scale digitization and computerized distribution of social activity (e.g. Sorensen 2017).

\subsection{Inter Disciplinary Practices for Disciplinary Evolution}

The second way in which disciplines evolve happens when scholars from one discipline engage with scholars from other disciplines (Abbott 2001) through the phenomena they study. For example, the problem of music piracy can be seen as one of unequal distribution of wealth, one of lack of access to 
education and skills, one of legal and regulatory frameworks, or one of ethics, depending on the disciplinary approach (economics, public policy, law, and ethics respectively). Such topical proximities can facilitate interaction among scholars from different disciplines, at the margins of each discipline. Thus, an economist studying the problem of music piracy, in trying to explain an observed correlation between poor people and people who pirate music, while focusing on the distribution of wealth, might also consider elements of public policy or law or ethics. Alternatively, a legal scholar, in trying to understand regulatory aspects of music copyright, might also examine the economic characteristics of geographical areas where people engage in music piracy, lack of education, and ethics. In studying a particular domain from different disciplinary positions, there takes place 'competition, accommodation, alliance and absorption' (Abbott 2001), as disciplines expand to meet each other. A discipline is therefore like an amoeba, putting out pseudopods as it moves into the spaces of other disciplines. Disciplines may thus be said to collide and intermingle with one another, with the outcome that each discipline may be extended with new topics, proximal to those studied by scholars in other disciplines.

The IS literature has attempted to address the issue of inter-disciplinary relations in a number of ways. The first involves considering the concept of reference or contributing disciplines (Keen 1980, Lee 2001). These are disciplines that provide theoretical or methodological frameworks that IS researchers draw from as they conceptualize research problems. Early studies showed the primary reference disciplines to be computer science, organizational science and management science (Culnan and Swanson 1986). More recent studies have pointed out the stretching and shifting of the boundaries of IS research, as topics and approaches have been drawn from a number of disciplines such as economics, psychology, sociology and strategy (Benbasat and Weber 1996, Vessey et al. 2002, DeSanctis 2003). However, and second, while insights from the reference disciplines are valuable, the stance of being informed by them potentially places IS researchers in the position of borrowing from, and yet not contributing to, them. Thus, scholars have suggested that not only should IS researchers acknowledge valuable sources of theory and method from other disciplines (Robey 2003), but the IS discipline should also serve as a reference to other disciplines (Baskerville and Myers 2003, Nambisan 2003). Notably, there is lack of agreement over whether or not this is actually 
happening (Bernroider et al. 2013, Grover et al. 2006, Wade et al. 2006). In addition and third, recent commentary calls for IS researchers to engage with wicked problems such as sustainability (e.g. Aanestad 2017). Such endeavours would need IS researchers to engage with different theoretical areas (e.g. Pries-Heje and Baskerville 2008), so as to imbibe a wider range of concepts and scholarly traditions in understanding both the organizational and societal significance of digital technologies. Finally, while there is growing recognition that IS research should be interdisciplinary (e.g. Bernroider et al. 2013), there is no clear articulation of what that means and how it can be done.

\section{THEORIZING KNOWLEDGE CONTRIBUTIONS IN INFORMATION SYSTEMS RESEARCH}

Through these two pathways, of intra-disciplinary perpetuation and of inter-disciplinary interaction, disciplines are enacted, constructed and reconstructed, and shape one another. They unfold both internally and in interaction with others. While studies broadly recognize the importance of each pathway in the IS discipline, as discussed above, there is no theoretically derived conceptualization of the particular types of knowledge contributions for each pathway. As a result, there is a lack of guidance regarding how IS researchers can create knowledge appropriate to each.

We theorize four types of contributions to knowledge that IS researchers can undertake, shown in Figure 1. These contributions qualify and classify the nature of IS research with a focus on specifying its intra-disciplinary and inter-disciplinary components. Our conceptualization is informed by concepts from texts on the development of disciplines (e.g. Abbott 2001, Kuhn 1970), and interdisciplinary research (e.g. Strober 2010, Derrida 1980).

<Figure 1 goes about here>

\subsection{Intra-disciplinary knowle dge contributions in IS}

As the IS discipline evolves, IS researchers would examine problems and create knowledge about a variety of topics within the discipline. This presents an opportunity to identify contributions that are internal to the IS discipline. We conceptualize these contributions to be of two types, namely, Single Disciplinary and Home Disciplinary. 


\section{Single Disciplinary}

We define a single disciplinary contribution to the IS discipline as one that draws on theories and concepts core to the IS discipline itself. Such a contribution incorporates an intra-disciplinary focus, and corresponds to the paradigmatic and cumulative tradition (Kuhn 1970). The literature inputs to the research that makes this type of contribution are dominated by existing IS disciplinary knowledge, drawn primarily from IS journals and texts. The outputs of the research focus on new IS disciplinary knowledge, i.e. knowledge that generates new insights about the design, use, management or impacts of an IT artefact (Straub 2010). Single discipline work does not primarily rely on reference disciplines.

\section{Home Disciplinary}

We define a home disciplinary contribution to the IS discipline as one that draws on theories and concepts both from the IS (or Home) discipline, as well as from other reference disciplines (Keen 1980, Lee 2001). The literature inputs to the research that makes this type of contribution include disciplinary knowledge from reference disciplines such as, for instance, psychology, sociology, strategy and organizational behavior, in combination with existing IS disciplinary knowledge. The outputs of the research focus on the generation of new IS disciplinary knowledge.

\subsection{Inter-disciplinary knowledge contributions in IS}

The design and use of IS pervades many interdisciplinary phenomena exemplified by wicked and urgent problems. To give an example, IS are important to sustainability because they can track, monitor and help influence people's behaviors regarding energy consumption, and facilitate the design and operation of smart energy grids. Understanding how the first can come about would require IS researchers to engage with disciplines such as sociology and public policy; examining the second would require dialogue with disciplines such as control and electrical engineering. A research problem that examines the design and benefits of smart grids therefore draws from all of these vastly different disciplines. Similarly, understanding how IS can facilitate social inclusion requires an investigation into the needs and behaviors of different segments of the population, such as remotely 
located, disabled or socially power-deprived people, requiring enquiry into different disciplines such as healthcare, gender studies and public services. Understanding such phenomena requires an understanding of both the design or use of particular IS and of the other disciplines, and is likely to result in contributions to knowledge that span one or more disciplines. IS research thus has an opportunity to inform other disciplines and address complex problems by engaging with research from these disciplines. We conceptualize such contributions to be of two types, namely, Cross Disciplinary and Interdisciplinary.

\section{Cross Disciplinary}

We define a cross disciplinary contribution as one that contributes new knowledge both to the IS discipline and to one or more reference disciplines. Similar to the home disciplinary contribution, the literature inputs to research that makes a cross disciplinary contribution include disciplinary knowledge from both other disciplines and IS. The IS discipline engages with the reference discipline's concepts and theories to produce interactional insights that enrich both (Oswick et al. 2011). The contribution to the reference discipline(s) is to extend existing concepts and relationships, usually in terms of conceptually new or modified IS-mediated or IS-enabled variables and/or relationships.

\section{Interdisciplinary}

We define an interdisciplinary contribution as one that develops fundamentally new, integrated or fused concepts that exist at the intersection and inter-subjective areas of different disciplines. In this case, those would be of the IS discipline and the other discipline $(s)^{3}$. The inputs to the research that makes an interdisciplinary contribution include disciplinary knowledge from IS and other disciplines. In order to make an interdisciplinary contribution, disciplinary concepts are brought to bear on

\footnotetext{
${ }^{3}$ Interdisciplinary research should be differentiated from multi-disciplinary work which involves solving a problem that requires practical expertise from different fields to be separately applied, rather than about creating knowledge at the intersection of different disciplines. An example of multi-disciplinary work would be building an oil rig that requires engineers and chemists to apply their know-hows. It is also to be differentiated from transdisciplinary work, which involves application of a theory or a concept, across disciplines. Such a theory or concept transcends disciplines and is therefore applicable in many fields. The disciplines do not contribute to the theory or concept, but provide settings in which to apply the transdisciplinary concept or theory. Examples of transdisciplinary concepts include general systems theory or structuration (Strober 2010).
} 
conceptual problems such that new interpretations for these concepts are created through cross fertilization, bricolage and critical encounters with different perspectives (Levi-Strauss 1966; Derrida 1980; Sumner 2003). Interdisciplinary contributions provide perspectives for examining disciplinary concepts in a relational way, through the particularity of their positions within a complex net of interrelations (Massey 1999) that characterize the research problem. They are formed and expressed through an integration of disciplinary insights (Sumner 2003, Porter et al 2006). Interdisciplinary contributions arise from approaches that focus on integration, non-reductionism, and free-play of theoretical concepts from different disciplines to create fused content (e.g. Derrida, 1980). They often produce cognitive or practical advancement for addressing a complex problem that spans many disciplines.

The IS discipline has been regarded as lying an intersection of different disciplines such as computer science and organization science, where scholarship is practiced by researchers from different backgrounds and interests (Keen 1980, Culnan and Swanson 1986). The phenomena studied by IS researchers are broad in scope, exhibit emergent properties and embody a variety of possible perspectives. Thus a number of studies have emphasized the importance of interdisciplinary contributions that IS researchers can potentially make (DeSanctis 2003, Galliers 2003).

\section{CLASSIFYING RESEARCH IN INFORMATION SYSTEMS}

In this section we examine how and to what extent our theorized knowledge contribution types find expression in recent IS research. For this purpose, we selected a representative set of papers published in IS journals, with the objective of analysing their contributions within the framing of this classification. Our data collection and analysis involved the following steps: (1) Paper selection; (2) Discipline code generation; and (3) Paper classification. We describe each step below.

\subsection{Step 1: Paper Selection}

We focused on a set of papers that represent high quality research conducted on a variety of topics in IS and published in journals that are readily accessible to IS scholars around the world. Therefore, we 
selected papers from the AIS basket of 8 journals: EJIS, ISJ, ISR, JAIS, JIT, JMIS, JSIS and MISQ ${ }^{4}$. These journals are deemed as being among the 'excellent' IS journals by the AIS'. To keep the total number of articles manageable and recent, we considered the five year period of 2010-2014. We created a corpus of 176 articles, which we deemed sufficient to identify trends with respect to the four different types, and which is similar to or greater than the size of the corpora created in previous work that sought to comment on IS research (e.g., Grover and Lyytinen 2015). The eight journals collectively published 1407 articles over the five year period. 176 represents approximately $12.5 \%$ or $1 / 8^{\text {th }}$ of these articles. Therefore, in order to select papers, we first created a list of all papers published by each journal over the five year period in chronological order, for a total of eight lists. We then selected every eighth paper in the sequence from each list. The effect of this sampling strategy is that each journal contributes a different number of papers to the corpus, proportional to the number of papers it published over the five year period. Table 1 in the Appendix shows: the total number of papers published in each of the eight journals over 2010-2014; the \% of the 1407 papers that these selected papers account for; the number of papers that we selected from each journal; and the \% of the 176 papers that the selected papers account for. We did not select papers that we classified as editorials, issues and opinions, research commentaries, philosophical perorations, and solely methodological in focus ${ }^{6}$. The papers included in the corpus cover a wide range of IS research topics across a variety of different levels of analysis, the major epistemological stances (positivist, interpretive, critical), and the primary functional perspectives (behavioural, design, technical).

\subsection{Step 2: Discipline Code Generation}

Next, we generated an initial list of code numbers for different disciplines as shown in Table 2 in the Appendix. The IS discipline was given a code of 1. Disciplines outside IS, but which IS scholars refer to, draw from or contribute to, and which were encountered in our corpus of 176 papers, were assigned codes from 2 through 25. The Management disciplines among these were classified

\footnotetext{
${ }^{4}$ EJIS - European Journal of Information Systems; ISJ - Information Systems Journal; ISR -Information Systems Research; JAIS - Journal of the AIS; JIT - Journal of IT; JSIS - Journal of Strategic IS; JMIS - Journal of MIS; MISQ - MIS Quarterly.

${ }^{5}$ http://aisnet.org/?SeniorScholarBasket. As a starting point we consider these journals and suggest that future studies could look at additional IS journals from other lists such as the Association of Business Schools list.

${ }^{6}$ Details of the exact papers we included in the corpus, as well as selection notes, are available from the authors.
} 
according to the UK Association of Business Schools journal guide (2015) ${ }^{7}$, which has an internationally representative coverage of topics and journals, and is widely accepted as a guide for authors and evaluators, for a range of management and related subject areas (Bernroider et al. 2013). The other disciplines, not captured by this list, were classified according to discipline classification lists provided by prior research (Biglan 1973) and by research funding councils in the US and UK ${ }^{8}$. A more detailed coding scheme was necessary for the IS discipline in order to classify and identify single disciplinary and home disciplinary IS contributions at the fractal level. We thus identified a further level of division in the form of various sub-disciplines of IS, such as IS adoption, IS use, IS security. These were given codes from 1.01 to 1.38 . For the non-IS disciplines, we used broad codes, so as to retain our IS focus and prevent unnecessary detail. We ensured that codes did not overlap, that is, each code was conceptually distinct from all other codes.

\subsection{Step 3: Paper Classification}

We next coded the 176 papers according to our classification. We undertook a multi-step and iterative process to code each paper as described below.

First, each of the two authors independently read each of the 176 papers to search for specific information that enabled classification of the contribution(s) of a paper as single disciplinary, home disciplinary, cross disciplinary or interdisciplinary. This reading was necessarily thorough and thus we read all sections of each paper in order to identify: (1) the nature of contribution; (2) the different IS sub-disciplines and non-IS disciplines covered; and (3) the theoretical contributions to each discipline. In order to classify papers, we defined the following codes. A paper was coded as: 'SD' if it made a single disciplinary contribution; 'HD' if it made a home disciplinary contribution; 'CD' if it made a cross disciplinary contribution; and 'ID', if it made an inter-disciplinary contribution at the intersection of the IS discipline and one or more other disciplines. A given paper could be assigned more than one code, based on the definitions of the four classification types. For example, if a paper

\footnotetext{
${ }^{7}$ http://charteredabs.org/academic-journal-guide-2015/

8 These include the Engineering and Physical Sciences Research Council (http://gow.epsrc.ac.uk/Research Topics Def.htm), Economic and Social Research Council (http://www.esrc.ac.uk/funding/guidance-for-applicants/is-my-research-suitable-for-esrc-funding/disciplineclassifications/) and National Science Foundation (http://www.nsf.gov/statistics/nsf00322/pdf/xwalk.pdf) classification lists.
} 
was coded as HD, it could in addition be coded as ID if it also made the latter type of contribution. A paper coded as CD could also be coded as ID if, in addition, an interdisciplinary contribution was made. A paper coded as ID could also be coded as HD if, in addition, it made a separate home disciplinary contribution to the IS discipline. Likewise, it could be coded as CD if it also made a separate contribution to another discipline ${ }^{9}$. Each paper was thus assigned a single code or a combination of codes. At the end of this step, each paper was classified as shown in Table 1.

\section{<Table 1 goes about here>}

The second step was to specify the IS sub-disciplines and other disciplines. To begin with, a research assistant in the disciplinary area of IS assigned the IS sub-discipline and discipline codes to each paper according to the code protocol described in Table 2 in the Appendix. To give an example of how this was done, one of the papers (Sun, 2010) contributed to the IS discipline with a focus on the IS-use sub-discipline (1.25) and drew from the reference discipline of Psychology (20). It was thus coded as 'HD', as shown in the first row of Table 3 in the Appendix. Another paper (Schlagwein and Bjørn-Andersen, 2014) contributed to IS with a focus on the IS-innovation sub-discipline (1.21). It also both drew from and contributed to the reference discipline of Organizational Behaviour (17). It was thus coded as 'CD'. At the end of this step, each paper was further assigned one or more of the discipline/sub-discipline codes from Table 2 in the Appendix, based on its contributions to the IS discipline (through the IS sub-disciplines) and other disciplines.

In the third step, each author independently reviewed all the assigned codes for the respective papers by re-checking the type of contribution and the assigned discipline codes. Occasionally discrepancies arose, where the authors initially disagreed on the codes. For instance, a paper that studied e-commerce behaviour from an economics or marketing perspective could potentially be classified as making a contribution to the disciplines of e-commerce, economics or marketing. The correct classification should reflect the nature of the contribution made in the paper, i.e. 'which is

\footnotetext{
${ }^{9}$ Some of the multi-code possibilities for any given paper are ruled out, according to the definitions of each contribution type. For example, a paper coded as SD would not also, by definition, be coded as HD or CD or ID. One coded as HD would not also be coded as SD or CD. A paper coded CD or ID would not also be coded as SD. However, a paper coded as HD or CD could also be coded as ID, and vice versa, that is, a paper coded as ID could also be coded as HD or CD.
} 
(are) the discipline(s) where the contribution(s) is (are) made?'. The authors addressed the discrepancies by intensively reading any such papers and then discussing the nature of the contribution. The list of disciplines and their respective codes was iteratively modified by each of the authors as they discussed the papers, identifying new codes and merging codes where appropriate. This process of discipline code and sub-code modification involved continuous discussions between the authors to resolve and clarify the codes and contributions. As a result of these discussions, on a few occasions the classification of a paper was changed, e.g. from HD to CD. Our objective was to achieve complete agreement on all the codes and coding classifications, rather than a statistical threshold value of inter-rater reliability. At the end of this process, for each paper, we recorded: (1) a paper identifier, e.g. MISQ 8, ISR 16, JMIS 24; (2) complete citation information; (3) the disciplines and sub-disciplines represented in the paper and the accompanying the codes; (4) the coding classifications of SD, HD, CD and ID with a 'yes' or a 'no'; (5) the codes for the specific IS subdisciplines and the non-IS reference disciplines that the paper referenced and contributed to; and (6) the final code/code-combination classification. To illustrate the outcome of the coding process, Table 3 in the Appendix provides these details for eight of the 176 papers in our corpus ${ }^{10}$, including the two mentioned above.

The above steps enabled us to engage in an intensive and rigorous analysis of each paper. Such an analysis was essential and necessary, given the evident detail and complexity required to be considered for identifying the knowledge contributions of each paper and for classifying it accordingly. Adhering consistently to this intensive and rigorous process for each paper enabled us to reach understanding and consensus as to the nature of each paper's contribution and to identify the IS sub-disciplines and non-IS disciplines involved. Table 1 provides a summary of the classifications and their counts for all the papers in our corpus. We find that $24 \%$ of the papers were classified as SD, implying that they contributed solely to the IS discipline and drew from IS literature for their motivation and background. The majority of the papers, $60 \%$, belonged to the HD classification. They referenced theories from other disciplines to explain phenomena implicated in the design, use and

\footnotetext{
${ }^{10}$ The complete set of papers and codes is available from the authors.
} 
management of IS. $13 \%$ of the papers exhibited a CD classification. With respect to ID, $3 \%$ of the papers had an HD-ID or CD-ID classification. No paper had a purely ID classification.

\section{ANALYSES AND INTERPRETATION: INTRA- OR INTER - DISCIPLINARY?}

Having examined the composition of our sample of recent IS research within the framing of our classification, we next analyse representative examples of each type in depth. Through our analysis, we explain what each type of contribution does and identify the different ways in which each is materialized.

\subsection{Single Disciplinary Research in IS}

In the 42 papers that were classified as SD, 20 IS sub-disciplines were recorded. A few subdisciplines occurred in multiple papers, e.g. E-Commerce (6 papers), IS Use (4 papers), and IS Adoption, IS Acceptance and Software Development (3 papers each).

The Single Disciplinary contribution in IS research is required for differentiation and generation of fractals. It is responsible for building a robust, cumulative body of IS research that embodies its disciplinary distinctiveness. From our analysis of our corpus of papers we find, as shown in Table 2, that this can be done in two ways: (1) investigating new IS topics and adding new IS sub-disciplines; and (2) applying and adapting exis ting IS concepts to explain new IS enabled phenomena.

\section{<Table 2 goes about here>}

With regard to the first way, increased devolution of IT in work and non-work activities means that IS researchers are investigating new phenomena, thus expanding into new sub-disciplines. For example, IS researchers have recently shown interest in the area of societal challenges (Majchrzak et al. 2014). This area could become a new IS sub-discipline, with investigations of new topics that relate to how IS can help address or create societal problems. Other new and related sub-disciplines could include, for example, well-being related effects of IS use, IS use in familial social units, and so on. These sorts of single disciplinary developments could generate new fractals and create new accumulations of knowledge in new IS sub disciplines. For instance, from our corpus we find, in Tow 
et al. (2010), an explanation of how and why users of social networking websites willingly disclose personal information, making possible new social media enabled phenomena such as cyberstalking.

Second, use of new IS artefacts and applications generates novel phenomena. New concepts and relationships are required to explain effectively how and why such phenomena play out. For instance, the use of the same smartphone for both work and non-work purposes creates IS-enabled entanglement between work and non-work settings. Understanding this entanglement would entail the pulling together of a number of traditional IS concepts such as task technology fit, IS use, IS functionality/affordance and IS enabled work processes, to develop new conceptual explanations of smartphone work and non-work use. As an example, Conger et al. (2013) examine the problem of information privacy in the context of use of Internet enabled transactions. They build on prior research on personal information privacy, which is largely confined to the interaction between the customer and the provider of goods and services. They introduce additional parties that are important to and can exert an influence on information privacy, such as legal data sharing partners and illegal entities, and explain how information privacy is affected by them. The paper contributes to SD research by proposing a new theoretical framework for understanding an existing IS phenomenon, i.e. information privacy, by drawing from existing IS concepts that include capabilities of emerging technologies and their use, but by new kinds of entities hitherto not studied.

\subsection{Home Disciplinary Research in IS}

The home disciplinary contribution to the IS discipline, which involves drawing on theories from other disciplines, constitutes the largest number of papers in our corpus. Of the 105 papers $(60 \%$ of our corpus) that we classified as HD, 29 IS sub-disciplines are recorded as constituting the home discipline. While a few sub-disciplines occur in multiple papers, e.g. E-Commerce (11 papers), IS Acceptance (7 papers), IS Use (14 papers), 7 sub-disciplines occur in only two papers each and 6 subdisciplines occur in only one paper each. 20 reference disciplines contribute to this body of HD research, with the more frequently occurring ones being Psychology (24 papers), Strategy (21 papers) and Economics (16 papers). 
Home-disciplinary IS research, in addition to considering the disciplinary distinctiveness of the IS field, recognizes and addresses the conceptual diversity of IS-enabled phenomena. Phenomena such as IS innovation or IS acceptance are IS-enabled manifestations of occurrences in other disciplines such as, in this case, organizational innovation and psychology, and require insights from them to be understood and explained. The objective of HD research is thus to explain and analyse diverse, rich and complex IS-enabled phenomena by bringing to bear insights from appropriate reference disciplines. As explained in Table 3, we find from the papers we analysed that this can be done in two ways: (1) investigating new IS-enabled phenomena and; (2) developing newly contextualized unde rstandings of IS-e nabled phenomena.

\section{$<$ Table 3 goes about here $>$}

For the first, in addition to the more common reference disciplines such as psychology and strategy, emerging technologies and the associated phenomena suggest the importance of reference disciplines not commonly considered in home disciplinary research. For instance it has been suggested that human-robot collaboration can be investigated using evolutionary theories (Yoo et al. 2010), and that IS-driven hyper-competition can be studied using complexity theory (Tanriverdi et al. 2010). From our corpus, Feller et al. (2012) draw from the concepts of innovation networks and brokerages from the Strategy literature, to explain how organizations can obtain intellectual property from individuals and firms they have no prior relationship with, contributing to an understanding of a new phenomenon, IS enabled crowdsourcing for innovation.

The second aspect of home disciplinary research is contextualization and illumination of the specific setting in which the IS phenomenon being studied takes place. While reference disciplines provide valuable theoretical insights, these insights were developed in contexts quite different from those where IS research is normally conducted and hence cannot be applied 'as is' to IS research problems (Lee 2001). Contextualizing can take the form of new constructs or relationships that adapt concepts or relationships from a reference discipline. For example, the concept of a 'capability' from the Strategy literature has been conceptualized as 'IS capability' or 'IS enabled capability' in IS research. Investigated over a number a studies (e.g. Bharadwaj 2000, Wade and Hulland 2004), IS capability has been conceptualized, defined, operationalized and tested specifically in order to explain 
IS related phenomena such as IS enabled competitive advantage and IS enabled innovation, contributing to rich, plausible and relevant understanding of such phenomena; such an understanding would not be possible without referencing the resource based view from Strategy and recontextualizing it to IS. As an example from our data, Ravishankar et al. (2013) study the phenomenon of offshoring through the anthropological lens of post-colonialism. The authors apply post-colonialism concepts such as social power differential to the context of IT offshoring to India, a former British colony. In doing so, they reveal a new understanding of the phenomenon of IT offshoring, different from the understanding previously articulated in the literature.

\subsection{Cross Disciplinary Research in IS}

In the 24 papers (13\% of our corpus) that we classify as cross disciplinary, 18 IS sub-disciplines are recorded as the home discipline to which the papers make a contribution. While a few of these subdisciplines have multiple occurrences, e.g. IS Capability (3 papers), IS Healthcare (2 papers), IS Implementation ( 3 papers) and IS Strategy ( 2 papers), all the others occurred only once. 11 non-IS disciplines are recorded as the disciplines that are enriched by the papers. Strategy occurred most frequently (8 papers), followed by Psychology and Organizational Behavior (4 papers), and Sociology (3 papers), with all other disciplines having only a single occurrence.

The objective of cross-disciplinary research is to contribute theoretically to both IS and other disciplines that study IS-enabled phenomena. In addition to the IS sub-discipline that it contributes to, it requires one or more reference disciplines, each of which benefits from or is morphed by it. We find from our analysis, and as shown in Table 4, that this can be done in two ways: (1) conceptualizing IS constructs and their relationships in ways that theoretically relate them to cons tructs and relationships in other disciplines; and (2) considering IS as a reference discipline that can theore tically inform phenome na and problems investigated in other disciplines.

\section{$<$ Table 4 goes about here >}

The first requires engaging in a process of two-way exchange between IS and the other disciplines in order to produce insights that are salient for each. Evolving IS capabilities create changes in the structure and dynamics of a number of phenomena studied in other disciplines, for 
example, group collaboration, which is influenced by use of IS. Conceptualizing IS centric constructs and relationships to analyse these changes would be a way to contribute to these disciplines. This can be done through a process where concepts from IS and the other discipline are analysed together to understand how they can interact with and change one another (Oswick et al. 2011). As an example from our corpus, Garfield and Dennis (2012) examine group development in the context of virtual teams whose interactions are mediated by IS applications. They find that groups that are not mediated through IS are able to continue using their original organizational routines and can thus quickly get up to speed in their group development. In contrast, IS-mediated groups find their original routines disrupted by IS and must adapt their work practices to its new features. They are slower to get going and follow a staged model of group development. In its cross disciplinary contribution, the authors show that IS-mediation influences the processes of group development (contribution to the IS discipline) and that group dynamics in teams depend on the particular IS and how it is used (a contribution to the Psychology discipline).

With regard to considering IS as a reference discipline, we note that the bodies of knowledge unique to the IS discipline include information systems management, development and use (Baskerville and Myers 2003). Cross disciplinary research should seek to apply these bodies of knowledge to understand emerging phenomena in other disciplines such as, for instance, smart manufacturing in operations management. The operations management discipline could draw from IS knowledge on systems design and use it to understand how the entanglement of information capturing devices and the design of assembly lines can affect the performance of manufacturing functions. Nambisan (2006) argues that IS could serve as a reference discipline for new product development with studies on the latter drawing from the system design, development and testing methodologies developed in the IS literature, to understand the development process of new products that have significant IT components in them.

As an illustration, Kane et al. (2014) juxtapose emerging platforms of IT-enabled social networks with an established typology of social networks to reveal how online social networks are theoretically distinct from those that are offline. The distinctiveness is shown to be based on the novel capabilities of social media platforms, which do not exist for traditional social networks. The 
contribution to the IS literature is made in terms of understanding the nature of social media enabled digital networks. The contribution to the sociology literature involves introducing and describing the new type of networks based on social media, informed by the theoretical properties of online networks.

\subsection{Inter Disciplinary Research in IS}

In our corpus, we found five papers in this category, one coded HD-ID and four coded CD-ID. These papers made contributions at the intersection of IS with operations management, psychology, sociology, and organization behaviour.

The objective of interdisciplinary research is to create transformative theoretical concepts and relationships by integrating theories and concepts from IS and other disciplines that challenge current formulations and interpretations through ontologically alternate ones. In the papers we analysed, we find that interdisciplinary contributions exist at the conceptual intersections or fusions of multiple disciplines and can be achieved in two ways: (1) revealing, describing and explaining ontologically new concepts and relationships that illustrate fusion or integration of ideas from multiple disciplines; and (2) integrating theories from different disciplines to apply to a conceptual problem. We illustrate these in Table 5.

\section{$<$ Table 5 goes about here>}

For the first, the integrated or fused idea can be a concept, a relationship between concepts or a process. As an example from the papers we analysed, Vaast et al. (2013) examine how new actor categories with new identities emerge in technology-mediated discourses such as blogging. Fusing the concepts of the social actor and the use of IS from the IS literature and identity from the sociology literature, the authors identify discursive practices through which new identities emerge through the use of social media tools such as blogging. This conceptualizes the identity formation process at the theoretical integration of media use practices, identity and media changes, and suggests that identity formation is an ongoing process of enactment that makes for fluid rather than settled identities. The concept of fluidity of identity is an interdisciplinary contribution that emerges as a fusion of ideas 
from each discipline and ontologically challenges the hitherto held notion of a stable and constant identity.

With regard to the second, the problem is usually a complex one. Strong et al. (2014) provide the example of the problem of understanding organizational change in a healthcare organization upon implementing an electronic health record (EHR) system. They integrate the theoretical concepts of affordances (sociology), materiality (sociology), the situated nature of IS use (IS), and the intentionality of the IS user (psychology), to develop a mid-range theory of organizational change from the implementation of EHR systems in healthcare organizations. The theory reveals new conceptual formulations from the integration of the respective disciplinary concepts, such as 'actualization of an affordance's potential' and 'bundles of inter-related affordances'. These new formulations are transformative in that they provide new and alternate theoretical organizing, from the fusion of the respective disciplinary organizing ideas, to understand and tackle the problem of why and how organizational change is enacted in healthcare organizations, as a result of EHR implementation.

\section{WAYS FORWARD: RECOMMENDATIONS AND IMPLICATIONS}

The research question that stimulated our work in this paper asks how IS research has addressed the twin challenges of, developing the IS discipline, while also engaging with other disciplines. In order to answer this question, we set out the following research objectives: develop a conceptualization of IS scholarship that offers both an intra-disciplinary and an inter-disciplinary view; investigate to what extent this conceptualization finds expression in current IS research; and provide guidance for IS scholars to implement the conceptualized scholarship. We addressed the first objective by theorizing a framework for classifying knowledge contributions in IS research, and the second by analysing the type of knowledge contributions of a five-year representative sample of papers from leading IS journals. We next address the third objective by drawing from our analysis to (1) articulate the importance and relevance of each type of contribution; and (2) explain how IS scholars, particularly researchers and editors, can practically incorporate these in their work. 


\subsection{Consolidating through Single Disciplinary and Home Disciplinary IS Research}

The Single Disciplinary and Home Disciplinary contributions are collectively predominant (84\%) in the corpus of papers we examined, which suggests that IS researchers are both familiar with this kind of research and well poised to continue undertaking it in future. These two types of contributions are valuable to the IS discipline because they embody areas of distinctiveness that IS researchers are uniquely capable of developing and deepening. They can be viewed as the sensing apparatus for exploring new IS phenomena to investigate and understand. They can enable IS researchers to consolidate and build on past accomplishments in IS research, thereby ensuring and sustaining its currency and relevance. How can IS researchers make these contributions?

We find that the distribution of the 30 IS sub-disciplines covered in these two types of contributions, is uneven (see Figure 2). 7 sub-disciplines (i.e. $22 \%$ ) account for $50 \%$ of the papers and $16(50 \%)$ for $80 \%$ of the papers. This suggests that most of the consolidation in intra-disciplinary IS research is taking place in a few areas, the top four being IS Use (18), E-Commerce (17), IS Acceptance (10) and Outsourcing (10). This type of concentration exemplifies a risk often associated with disciplinary consolidation: that of 'expected and unsurprising' findings (Foster et al 2015), largely from literature-based gap-spotting (Sandberg and Alvesson 2011), i.e., from testing relationships among known IS constructs, or known IS relationships in different settings within only a few IS sub-disciplines. To address this potential problem, IS researchers engaged in these two types of research should investigate phenomena and problems in a wider variety of existing sub-disciplines and develop new sub-disciplines. They should be alert to emerging technologies and their use and examine the associated phenomena not just through the conceptual lenses of existing IS constructs and relationships but also by conceptualizing new constructs and relationships. For example, while the phenomenon of bringing one's own devices to work can have implications for IS security (an existing sub-discipline), it could also have effects on technostress (potentially emerging sub-discipline). While it is may be easier to work in the limited number of IS sub-disciplines that have a larger base of literature, doing so runs the alarming risk of neglecting new IS phenomena altogether. 
Second, IS researchers should develop theoretical linkages between IS sub-disciplines. This is both because IS sub-disciplines can enrich one another and because many IS phenomena span multiple IS sub-disciplines. In terms of the former, sub-disciplines such as IS implementation, IS use and IS resistance can find conceptually enriching common ground. In terms of the latter, understanding how a firm can acquire and maintain competitive advantage from IT, for instance, spans the sub-disciplines of, among others, IS strategy, IS capability and IS alignment. On examining the number of different IS sub disciplines covered in each paper that made a single or home disciplinary contribution $(n=150)$, we find that the maximum is 4 , minimum 0 , average 1.01 , and mode 1; 122 papers have one IS sub-D. This lack of multiple IS sub-disciplines in a single paper suggests that IS phenomena are perhaps not being investigated in their full richness and complexity, reinforcing the concern about narrowly conceptualized research questions.

Third, IS researchers should strive for disciplinary distinctiveness and IS specificity in the constructs and relationships they conceptualize when making the Home Disciplinary contribution. A recent commentary (Grover and Lyytinen 2015) focusing on two of the journals that we include in our corpus provides evidence of a strong epistemic trend of simply 'borrowing' concepts, relationships and operationalisations from reference theories with minimal theoretical modification, and of failing to engage in theoretical and empirical articulations of the distinctiveness of the IS phenomena examined. This is a pitfall that IS researchers seeking to make the Home Disciplinary contribution can easily fall into, or perhaps have actually fallen into. Going forward, this can be avoided by theoretically modifying and extending the concepts of the contributing discipline's that they draw from.

Relatedly, IS journals should be mindful of how they wish to represent the various subdisciplines. For instance, editors could decide to focus on specific IS sub-disciplines as points of distinctiveness in a particular journal or alternatively encourage the submission of manuscripts that investigate new IS sub-disciplines or the relationships among them. 


\subsection{Boundary Spanning through Cross Disciplinary and Interdisciplinary IS Research}

Our analysis revealed a relatively small incidence of the Cross Disciplinary and Interdisciplinary types of research, suggesting IT researchers' relative lack of engagement with them. These two types of contribution are the means through which the IS discipline can engage with other disciplines, by mutually enriching other disciplines and by addressing complex research problems that require intellectual resources from different disciplines. The disciplines that were most enriched by the papers in our corpus included Strategy (8), Organizational Behaviour (4), Psychology (4) and Sociology (2), and the disciplines that were most borrowed from included Psychology (25), Strategy (23), Economics (18) and Organizational Behaviour (18) (see Figure 3). While a number of scholars have stressed that IS research should theoretically engage with and enrich other disciplines (e.g. Robey 2003, Galliers 2003, Baskerville and Myers 2003, DeSanctis 2003, Wade et al. 2006, Bernroider et al. 2013), there is a lack of critical reflection and guidance on how this can be achieved. To do this, it is important to understand the challenges and dialectal tensions associated with inter-disciplinary knowledge contributions.

Firstly, the kinds of problems that are more naturally amenable to interdisciplinary research are difficult to conceptualize, not least because of disciplinary and professional imperatives that require clear and specific disciplinary contributions to each discipline. Conceptual integration that takes into account disciplinary advancements is not easy to produce. It creates fused knowledge from which it can be difficult to untangle the specific contributions to each discipline. All of this raises the question of where IS researchers can publish such contributions. Baskerville and Myers (2003) suggest that IS researchers who contribute to other disciplines should consider publishing their work in the journals of those disciplines. As a practical recommendation and as illustrated by the papers in our analysis, IS researchers who wish to make the Cross Disciplinary contribution should specify the contributions to each discipline. They can then publish the IS focused contributions in IS journals and the reference discipline-focused contributions in the appropriate disciplinary journals. For the Interdisciplinary research contribution, we suggest two guidelines from our analysis. One is to situate the contribution in the context of design or use of IS (Carlo et al. 2012; Vaast et al. 2013) or frame it 
as an explanation of a phenomenon that is enabled by IS implementation and use (Strong et al. 2014).

Both would render it appropriate for an IS journal. Another approach is to contribute to journals that specifically publish interdisciplinary research ${ }^{11}$. Such journals often focus on a particular domain of human activity and are more open to unconventional theoretical formulations emanating from disciplinary integration that would address problems in that domain. In the case of the Interdisciplinary contribution that is focussed on addressing a specific problem, IS researchers should be careful to specify the IS research contribution and distinguish it from the problem solving or consulting aspect of the project. They may find that problem-focused research is too situated and limited by time and context to produce enduring disciplinary knowledge that is portable across problems (Abbott 2001), unless they make efforts to generalize their findings from their immediate context to a new theory that they develop or to an existing theory that they broaden with their new findings (Davison and Martinsons, 2016; Lee and Baskerville 2003).

Secondly, the Cross disciplinary and Interdisciplinary contributions require researchers from different disciplines to collaborate because there are cognitive and intellectual limits to the extent a group of researchers from the same discipline can make these kinds of contributions. It is easy enough to suggest that IS researchers wishing to make these contributions should collaborate with colleagues from other disciplines. However, there are significant systemic barriers to this, such as different or even incompatible styles of thought, research training, methods, traditions, vocabulary, disciplinary socialization, and assessment of contribution (Jacobs and Friekel 2009; Strober 2010; Robey 1996); this can lead to epistemological and methodological conflict. It may be easier to collaborate with colleagues from disciplines traditionally within business and management schools; the Cross Disciplinary contribution to these disciplines are therefore likely to be more common for IS researchers. On the other hand the Interdisciplinary contribution may require collaboration not only with academics from disciplines such as engineering and design, but also with partners from industry; in both cases, the disciplinary disparity from IS is much greater.

\footnotetext{
${ }^{11}$ An example is the 'Mobilities' Journal, http://www.tandfonline.com/loi/rmob20, that focuses on how individuals and organizations negotiate and enact mobility. It publishes interdisciplinary contributions that focus on the impact of various mobility enabling technologies ranging from smartphones, self-driving cars and bicycles, spanning, for example, the disciplines of Sociology, Management, IS, and Science and Technology Studies.
} 
Thirdly, institutional structures and activities that help foster interdisciplinary collaborations include research centers, research clusters and funding applications. Senior IS scholars should actively influence their institutional environments where possible to provide support for these.

Finally, the Cross Disciplinary and Interdisciplinary contributions pose distinctive issues for journal editors and editorial boards to consider. Should IS journals encourage their submission? Such research is difficult to review from traditional disciplinary viewpoints and is often regarded as not having contributed substantially to any of the disciplines involved (Mansilla 2006). To the extent that there are few IS researchers making these contributions, it is hard to find reviewers who can review them. Editorial strategies could include sections especially devoted to the Cross Disciplinary or Interdisciplinary contributions, and the appointment of more outward-looking scholars with a track record that indicates competence from both the IS discipline's and other disciplines' point of view, to editorial boards. The creation of a new journal for IS related Cross Disciplinary and Interdisciplinary contributions, is also an option.

\subsection{Looking Inward or Outward?}

Increasingly, there are conflicts between what research funding councils are asking for (i.e. problemfocused Cross Disciplinary and Interdisciplinary research) and what IS scholars and academics find it important, or just easier, to contribute to (i.e. Single Disciplinary and Home Disciplinary research). With ever more research being directed through funding from research councils, which require interdisciplinary research proposals, this is an important matter for established academics, junior faculty, as well as doctoral students.

Should IS researchers make a choice? While there is no silver bullet for this dilemma, IS researchers should consider the following factors. First, given the cognitive efforts required for multidiscipline understanding, benefits to single discipline specialisation include higher productivity. On the other hand, interdisciplinary contributions can have greater citation-related impact and visibility (Uzzi et al 2013, Lamont 2009). Second, research shows that academic career advancement in a specific discipline is influenced by discipline-specific, but not interdisciplinary, collaboration (Van Rijnsoever and Hessels 2011). Thus, academic structures and managers are likely to place primacy on publications in the scholar's home discipline. Third, lists of journals that are relied on for tenure and 
promotion cases are more often than not discipline-specific ${ }^{12}$; evaluating research published in other journals places an overhead on tenure and promotion committees that may not always be welcome. Publishing in journals of other disciplines may thus not be appreciated by tenure and promotion boards.

We stress that both intra- and inter-disciplinary IS contributions are important. Nevertheless, each carries potential risks and pitfalls. The latter exemplifies the critical role of IS as a key constituent of solutions to complex societal issues such as emergency response, counter-terrorism surveillance, sustainable living, smart cities, and so on, and to engage with other communities of scholars to jointly address these problems. Given current institutional paradigms in most universities across the world, scholars who are post-tenure may be better placed to take on the task of making these types of contributions. The former is necessary to be successful in the disciplinary structure where IS scholars work and the associated expectations for tenure and promotion. Junior faculty may find it more prudent to make intra-disciplinary IS contributions, especially at the beginning of their careers. IS departments that have large numbers of academics and doctoral students should instil and develop in their members a range of values and research skills that can enable them to consider and undertake both intra- and interdisciplinary contributions.

\subsection{Publishing Indirect IS Contributions in IS Journals or non-IS Journals?}

So far we have discussed papers which made one of the four types of contributions to the IS discipline. However, our corpus also had a set of papers that did not make a contribution to the IS discipline at all. Four papers had a Single Disciplinary contribution that was to non-IS disciplines: two each in Marketing and Strategy. Twelve papers had a Home Disciplinary contribution where neither the discipline contributed to (i.e. home discipline), nor the discipline referenced from, was IS. The home disciplines were Marketing (7), Strategy (3), Operations Management (1) and Law (1), and the reference disciplines were Economics (9), and one each for Psychology, Strategy and Operations Research. This prompted us to ask - Why would these papers find their way to IS journals? Looking

\footnotetext{
${ }^{12}$ In the US and many Asian countries, IS departments in most universities refer to some version of lists of ISspecific journals such as the AIS Senior Scholars basket. Universities in the EU and Australia similarly consider lists of IS -specific journals. Universities in the UK are more flexible in that they consider the ABS list, which includes journals from other management disciplines as well.
} 
for an answer, we found that the research contributions in these papers were indirectly, rather than directly related to IS; they considered not the design, implementation or use of IS, but the marketing of digital products such as music or the strategy choices of IT services firms. For example, two of the Single Disciplinary contributions to the marketing literature consisted of identifying successful strategies for the marketing of apps and digital music respectively. One of the Home Disciplinary contributions (in Strategy) was to examine diversification choices for IT firms and another (in Law) was in understanding how digital music piracy was socially influenced. In all cases, IS was indirectly implicated through a digital product or service, or their producers and consumers. Such papers would be of interest to the respective disciplines to which they make their contribution, but whose researchers may not read IS journals.

There was another set of papers which made a Home Disciplinary contribution to another discipline, with the reference discipline being IS. The other disciplines included Operations Management (3), Strategy (4), Law (1) and Finance (1). As an example, one of them studied how operations in healthcare are improved using healthcare IT, drawing from IS concepts such as system resistance and avoidance of use. These papers showcased the value of IS as a reference discipline. Publishing them in journals of the respective disciplines may increase the citations of important and relevant IS topics in journals of other disciplines. This has been a thorny and contentious matter for IS researchers and a subject of much debate (Baskerville and Myers 2003, Grover et al 2006, Wade et al 2006).

Clearly, IS researchers who wish to make the Single or Home Disciplinary contributions to other disciplines should consider publishing in the respective disciplinary journals. From our corpus, marketing (9), operations management (3) and strategy (8) appear to be the more prominent. While this may lessen the count of a researcher's IS publications, it may lead to greater impact and visibility of their contributions among relevant readers. Relatedly, editors and editorial boards of IS journals must consider policies regarding how papers making these sorts of contributions can be developed and supported in a way that increases their visibility in the respective disciplines, and whether or not they should be published in IS journals. 


\subsection{Future Extensions and Limitations}

Our study is limited in some ways. First, it does not consider journals outside the IS discipline that publish IS research contributions. Thus it may have an under-representation of the Cross Disciplinary and Interdisciplinary IS contributions, which may have been published in these journals. We find from Figure 3 that Psychology, Strategy, Organizational Behaviour and Sociology were the disciplines most represented in the Cross Disciplinary contribution. Future studies could include journals from these disciplines, as well as those that publish research in more than one discipline, including IS ${ }^{13}$, to consider a wider representation of journals that can potentially publish these types of contributions. Second, while we focus on research articles; we do not include the work of specific authors who publish IS related contributions in journals of other disciplines. Third, and relatedly, we do not study IS contributions of researchers from other disciplines, published in journals from other disciplines. Such contributions would be classified as Home Disciplinary if published in an IS journal. It would be interesting for future studies to investigate if such papers acknowledge or invite dialogue with papers in IS journals on the same topic.

Notwithstanding these limitations, our study provides a springboard for future work and reflection by IS scholars in a number of ways. First, our theorization of the four types of contributions can be used by IS scholars, editors and doctoral students to assess and evaluate the kind of research they wish to undertake and publish, and strategize its framing. Second, we note that like any other discipline, the IS discipline is perpetually configured and re-configured by the deliberate and convergent actions of IS scholars. The disciplinary world that the IS discipline seeks to understand is not an arbitrary or static construction; IS scholars are responsible for its continual (re) emergence. Our study prompts them to (1) reflect on their knowledge creating choices; (2) potentially select choices that they find appropriate; and (3) consider corresponding knowledge creating practices. In doing so, it provides guidance to researchers and editors to reconsider and change the objectives, practices, and ambit of their work. Third, scholars have suggested that, but not explained how, the IS discipline should examine the content and domain of its scholarship on an ongoing basis (e.g. Robey 2003). Our

\footnotetext{
${ }^{13}$ Management Science, Decisions Sciences Journal and IEEE Transactions on Engineering Management, for example
} 
study can be used as a basis for understanding and describing the state of IS research during various time periods, vis-a-vis its proclivity towards intra-disciplinary and inter-disciplinary knowledge contributions. While we find from our study a predominance of intra-disciplinary contributions, a similar exercise conducted at a future time and with a different set of papers may reveal a different distribution.

\section{A WIDE WORLDVIEW OF INFORMATION SYSTEMS RESEARCH}

We suggest that IS researchers should generate knowledge that is both specific to our own discipline and that informs other disciplines, according to the four types we conceptualize. We envision IS, as we show in Figure 4, as a flexibly stable discipline that has both (1) a consolidated deep structure (through the Single and Home disciplinary contributions); and (2) a periphery of flux (through the Cross and Inter disciplinary contributions). We argue for a novel and broad worldview, a Weltanschauung of the IS discipline that can leverage the value of both intra and inter-disciplinary contributions, reflected in the four types of knowledge contributions.

Scholarship confined to a single discipline consists of asking relatively narrow and focused questions with the objective of getting more accurate answers. However in such a case, 'extraordinary problems are not to be had for the asking' (Kuhn 1970). While it is helpful, as past studies commenting on IS have done, to point out the dialectics between the idea of a cumulative tradition that defines a core set of IS topics and that of a flexible core that permits a broad range of IS topics, it is time to acknowledge that what is needed is to be both interdisciplinary and yet retain and strengthen an IS core. We start a conversation about how that can be done. We provide practical guidance for IS scholars in planning their research strategies for both Intra- and Inter-disciplinary IS knowledge contributions. In doing so, we articulate ways to break the 'vicious cycle' of the dominant, scripted type of IS theorization that primarily replicates concepts from other disciplines, as recently reported in two of the IS discipline's top journals (Grover and Lyytinen 2015).

In conclusion, IS researchers should forcefully and clearly articulate the role of the IS discipline in the complex and inter-dependent disciplinary ecosystem that is emerging to tackle the business and societal problems of our times. The IS discipline needs a robust disciplinary core that is 
strong in its indigenous understanding of IS phenomena together with a supple and open-minded disciplinary boundary that can confidently engage with other disciplines. In order for that to happen, IS researchers should mindfully consider, not only what they wish to study, but also to frame their knowledge contributions appropriately, and publish them strategically. It is our hope that our conceptualization and illustration of the four types of IS knowledge contributions and guidance regarding their practice speak both to the perpetuation of IS as a discipline and to its relevance in a wider, interdisciplinary world.

\section{REFERENCES}

Aanestad, M. (2016) "How IS can become more Agile and Relevant," Scandinavian Journal of Information Systems (28:2), Article 4.

Abbott, A. 1988. The System of Professions: An Essay on the Division of Expert Labor. Chicago: University of Chicago Press.

Abbott, A. 2001. Chaos of Disciplines. Chicago: University of Chicago Press.

Agarwal, R., and Lucas, H.C. 2005. "The Information Systems Identity Crisis: Focusing on HighVisibility and High-Impact Research", MIS Quarterly (29:3), pp. 381-398.

Barua, A., and Mani, D. 2014. "Augmenting Conflict Resolution with Informational Response: A Holistic View of Governance Choice in Business Process Outsourcing", Journal of Management Information Systems (31:3), pp. 72-105.

Baskerville, R.L., and Myers, M.D. 2003. "Information Systems as a Reference Discipline", MIS Quarterly (26:1), pp. 1-14.

Benbasat, I., and Weber, R. 1996. "Research Commentary: Rethinking .Diversity in Information Systems Research", Information Systems Research (7:4), pp. 389-399.

Benbasat, I., and Zmud, R.W. 2003. "The Identity Crisis within the IS Discipline: Defining and Communicating the Discipline's Core Properties", MIS Quarterly (27:2), pp. 183-194.

Bernroider, E., Córdoba, J.R., and Pilkington, A. 2013. "Research in Information Systems: A Study of Diversity and Inter-Disciplinary Discourse in the AIS Basket Journals between 1995 and 2011", Journal of Information Technology (28:1), pp. 74-89.

Bharadwaj, A.S. 2000. "A Resource-Based Perspective on Information Technology Capability and Firm Performance: An Empirical Investigation”, MIS Quarterly (24:1), pp. 169-196.

Biglan, A. 1973. "The Characteristics of Subject Matter in Academic Areas, Journal of Applied Psychology “(57:3), pp. 195-203.

Bryant, A. 2008. "The Future of Information Systems: Thinking Informatically", European Journal of Information Systems (17:6), pp. 695-698.

Carlo, J.L., Lyytinen, K., and Boland, R.J. 2012. "Dialectics of Collective Minding: Contradictory Appropriations of Information Technology in a High-Risk Project", MIS Quarterly (36:4), pp. 1081-1108.

Clarke, R. 2015. "Not Only Horses Wear Blinkers: The Missing Perspectives in IS Research", Keynote Address delivered at the $26^{\text {th }}$ Australasian Conference on Information Systems, Adelaide, Australia, Nov 29 - Dec 4.

Conger, S., Pratt, J.H., and Loch, K.D. 2013. "Personal Information Privacy and Emerging Technologies", Information Systems Journal (23:5), pp. 401-417.

Culnan, M.J,. and Swanson, E.B. 1986. "Research in Management Information Systems, 1980-1984: Points of Work and Reference", MIS Quarterly (10:3), pp. 289-302.

Daft, R.L., and Lewin, A.Y. 2008. "Rigor and Relevance in Organization Studies: Idea Migration and Academic Journal Evolution", Organization Science (19:1), pp. 177-183. 
Davis, F.D. 1989. "Perceived Usefulness, Perceived Ease of Use, and User Acceptance of Information Technology", MIS Quarterly (13:3), pp. 319-340.

Davison, R.M., and Martinsons, M.G. (2016) Context is King! Considering Particularism in Research Design and Reporting, Journal of Information Technology (31:3), pp. 241-249.

Derrida, J. 1980. "Structure, Sign and Play in the Discourse of the Human Sciences", in: Derrida, J. (Ed) Writing and Difference, Chicago: University of Chicago Press.

DeSanctis, G. 2003. "The Social Life of Information Systems Research, A Response to Benbasat and Zmud's Call for Returning to the IT Artifact", Journal of the Associationfor Information Systems (4:7), pp. 360-376.

Dhillon, G.S., Caldeira, M., and Wenger, M.R. 2011. "Intentionality and Power Interplay in IS Implementation: The Case of an Asset Management Firm", Journal of Strategic Information Systems (20), pp. 438-448.

Feller, J., Finnegan, P., Hayes, J. and, O’Reilly, P. 2012. “Orchestrating' Sustainable Crowdsourcing: A Characterisation of Solver Brokerages", Journal of Strategic Information Systems (21), pp. 216-232.

Galliers, R. 2003. "Change as Crisis or Growth? Toward a Trans-Disciplinary View of Information Systems as a Field of Study: A Response to Benbasat and Zmud's Call for Returning to the IT Artifact", Journal of the Association for Information Systems (4:6), pp. 337-351.

Garfield, M.J., and Dennis, A.R. 2012. "Toward an Integrated Model of Group Development:

Disruption of Routines by Technolgy-Induced Change", Journal of Management Information Systems (29:3), pp. 43-86.

Grover, V., and Lyytinen, K. 2015. "New State of Play in Information Systems Research:The Push to the Edges", MIS Quarterly (39:2), pp. 271-296.

Grover, V., Ayyagari, R., Gokhale, R., Lim, J., and Coffey, J. 2006. "A Citation Analysis of the Evolution and State of Information Systems Within a Constellation of Reference Disciplines", Journal of the Association for Information Systems (7:5), pp. 270-324.

Jacobs, J. A., and Frickel, S (2009), Interdisciplinarity: A Critical Assessment, Annual Review of Sociology 2009, 35, pp. 43-65.

Kane, G.C., Alavi, M., Labianca, G., and Borgatti, S.P. 2014. "What's Different About Social Media Networks? A Framework and Research Agenda", MIS Quarterly (38:1), pp. 275-304.

Keen, P.G.W. 1980. "MIS Research: Reference Disciplines and A Cumulative Tradition" in:

Proceedings of the First International Conference on Information Systems, Philadelphia, PA, pp. 9-18.

Kreps, D. 2010. "My Social Networking Profile: Copy, Resemblance, or Simulacrum? A Poststructuralist Interpretation of Social Information Systems", European Journal of Information Systems (19:1), pp. 104-115.

Kuhn, T.S. 1970. The Structure of Scientific Revolutions, 2nd Edition, Chicago and London: The University of Chicago Press.

Lamont, M. 2009. How Professors Think: Inside the Curious World of Academic Judgment. Cambridge, MA: Harvard University Press

Laudon, K., and Laudon, J. 2014. Management Information Systems. Managing the Digital Firm $13^{\text {th }}$ Ed. Upper Saddle River, New Jersey: Pearson Higher Education.

Lee, A.S. 2001. "Editor's Comments", MIS Quarterly (25:1), pp. iii-vii.

Lee, A.S., and Baskerville, R.L. 2003. "Generalizing Generalizability in Information Systems Research", Information Systems Research (14:3), 221-243.

Levi-Strauss, C. 1966. The Savage Mind, Chicago: University of Chicago Press.

Majchrzak, A., Markus, M.L., and Wareham, J. 2014. "Call for Papers, Special Issue on ICT and Societal Challenges", MIS Quarterly. http//www.misq.org/skin/frontend/default/misq/pdf/ CurrentCalls/ICTChallenges.pdf

Mansilla, V.B. 2006. "Symptoms of Quality: Assessing Expert Interdisciplinary Work at the Frontier: An Empirical Exploration", Research Evaluation (15:1), 17-29.

Massey, D. 1999. "Negotiating Disciplinary Boundaries”, Current Sociology, 47, 4, 5-12.

Mills, C.W. 91959) The Sociological Imagination, Oxford University Press. 
Nambisan, S. 2003. "Information Systems as a Reference Discipline For New Product Development", MIS Quarterly (27:1), 1-18.

Orlikowski, W.J., and Iacono, C.S. 2001. 'Research Commentary: Desperately Seeking the 'IT' in IT Research: A Call to Theorizing the IT Artifact”, Information Systems Research (12:2), pp. 121-134.

Oswick, C., Fleming, P., and Hanlon, G. 2011. "From Borrowing to Blending: Rethinking the Process of Organizational Theory Building”, Academy of Management Review (36:2), pp. 318-337.

Ravishankar, M.N., Pan, S.L., and Myers, M.D. 2013. "Information Technology Offshoring in India: A Postcolonial Perspective”, European Journal of Information Systems (22:4), pp. 387-422.

Robey, D. 1996. "Diversity in Information Systems Research:Threat, Promise, and Responsibility", Information Systems Research (7:4), pp. 400-408.

Robey, D. 2003. 'Identity, Legitimacy and the Dominant Research Paradigm: An Alternative Prescription for the IS Discipline: A Response to Benbasat and Zmud's Call for Returning to the IT Artifact", Journal of the Association for Information Systems (4:7), pp. 352-359.

Sandberg, J., and Alvesson, M., 2011 Ways of constructing research questions: gap-spotting or problematization? Organization (18:1), pp.23-44

Schlagwein, D. and Bjørn-Andersen, N. 2014. "Organizational Learning with Crowdsourcing: The Revelatory Case of LEGO”, Journal of the Association for Information Systems (15:11), pp. 754-778.

Sein, M.K., Henfridsson, O., Purao, S., Rossi, M., and Lindgren, R. 2011. “Action Design Research”, MIS Quarterly (35:1), pp. 37-56.

Sørensen, C. (2016) "The Curse of the Smart Machine? Digitalisation and the children of the mainframe," Scandinavian Journal of Information Systems (28:2), Article 3.

Stafford, T.F., and Turan, A.H. 2011. "Online Tax Payment Systems as an Emergent Aspect of Governmental Transformation”, European Journal of Information Systems (20:3), pp. 343357.

Straub, D.W. 2010. “Editor's Comments: MISQ, Inc. or an Online Collective? Is There a Journal Personality and What it Means for Authors?", MIS Quarterly (34:3), pp. iii-viii.

Strober, M.H. 2010. Interdisciplinary Conversations: Challenging Habits of Thought, Palo Alto, CA: Stanford University Press.

Strong, D.M., Johnson, S.A., Tulu, B., Trudel, J., Volkoff, O., Pelletier, L.R., Bar-On, I., and Garber, L. 2014. "A Theory of Organization-EHR Affordance Actualization", Journal of the Association for Information Systems (15:2), pp. 53-85.

Sumner, J. 2003. "Relations of Suspicion: Critical Theory and Interdisciplinary Research", History of Intellectual Culture (3:1), pp. 1-12.

Sun, H.S. 2010. "Sellers' Trust and Continued Use of Online Marketplaces", Journal of the Association for Information Systems (11:4), pp. 182-211.

Tanriverdi, H., Rai, A., and Venkatraman, N. 2010. "Reframing the Dominant Quests of Information Systems Strategy Research for Complex Adaptive Business Systems”, Information Systems Research (21:4), pp. 822-834.

Tow, W.N.F.H., Dell, P., and Venable, J. 2010. "Understanding Information Disclosure Behaviour in Australian Facebook Users", Journal of Information Technology (25:2), pp. 126-136.

Tiwana, A., and Konsynski, B.R. 2010. "Complementarities Between Organizational IT Architecture and Governance Structure”, Information Systems Research (21:2), pp. 288-304.

Uzzi, B., S. Mukherjee, M. Stringer, and B. Jones, 2013. Atypical combinations and scientific impact. Science, 342,pp. 468-472.

Vaast, E., Davidson, E.J., and Mattson, T. 2013. "Talking about Technology: The Emergence of a New Actor Category through New Media", MIS Quarterly (37:4), pp. 1069-1092.

Van Rijnsoever, F. J., and Hessels, L. K. (2011), Factors associated with disciplinary and interdisciplinary research collaboration, Research Policy, 40, pp. 463-472

Venkatesh, V., Morris, M.G., Davis, G.B., and Davis, F.D. 2003. "User Acceptance of Information Technology: Toward a Unified View", MIS Quarterly (27:3), pp. 425-478. 
Vessey, I., Ramesh, V., and Glass, R. 2002. "Research in Information Systems: An Empirical Study of Diversity in The Discipline and Its Journals", Journal of Management Information Systems (19:2), pp. 129-174.

Wade, M., Biehl, M., and Kim, H. 2006. "Information Systems is Not a Reference Discipline (and What We Can Do About It)", Journal of the Association for Information Systems (7:5), pp. 247-269.

Weick, K.E. 1995. Sensemaking in Organizations. Thousand Oaks, CA: Sage.

Yoo, Y., Henfridsson, O., and Lyytinen, K. 2010. "The New Organizing Logic of Digital Innovation: An Agenda for Information Systems Research", Information Systems Research (21:4), pp. 724-735.

Young, M.L., Kuo, F.Y., and Myers, M.D. 2012. "To Share or Not to Share? A Critical Research Perspective on Knowledge Management Systems", European Journal of Information Systems (21:5), pp. 496-511. 
Figure 1: Intra-disciplinary and Inter-disciplinary research in Information Systems

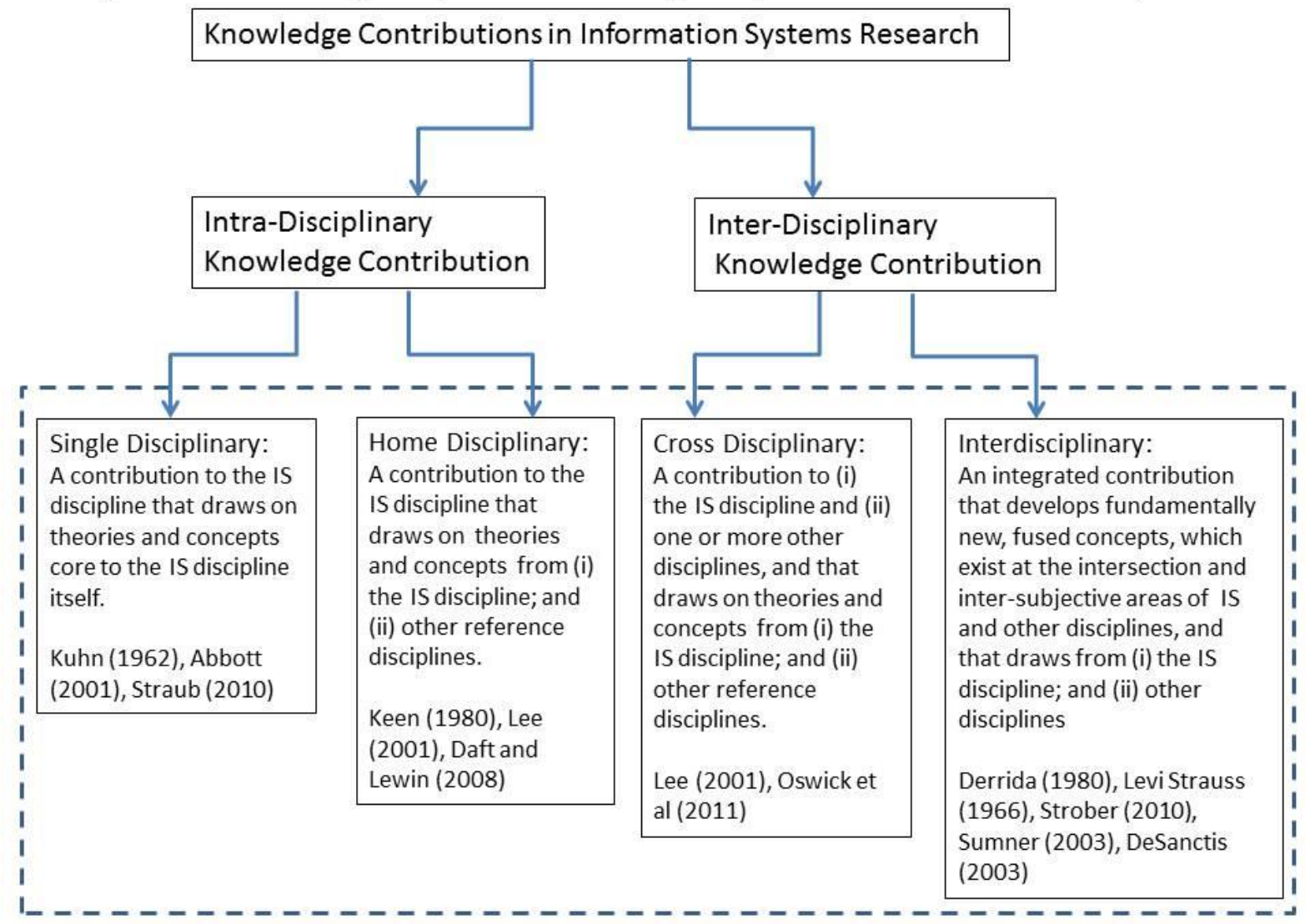


Figure 2: IS Sub-Dis ciplines by Extent of Consolidation: Distribution of IS Sub-Disciplines in the Single and Home Disciplinary Contributions

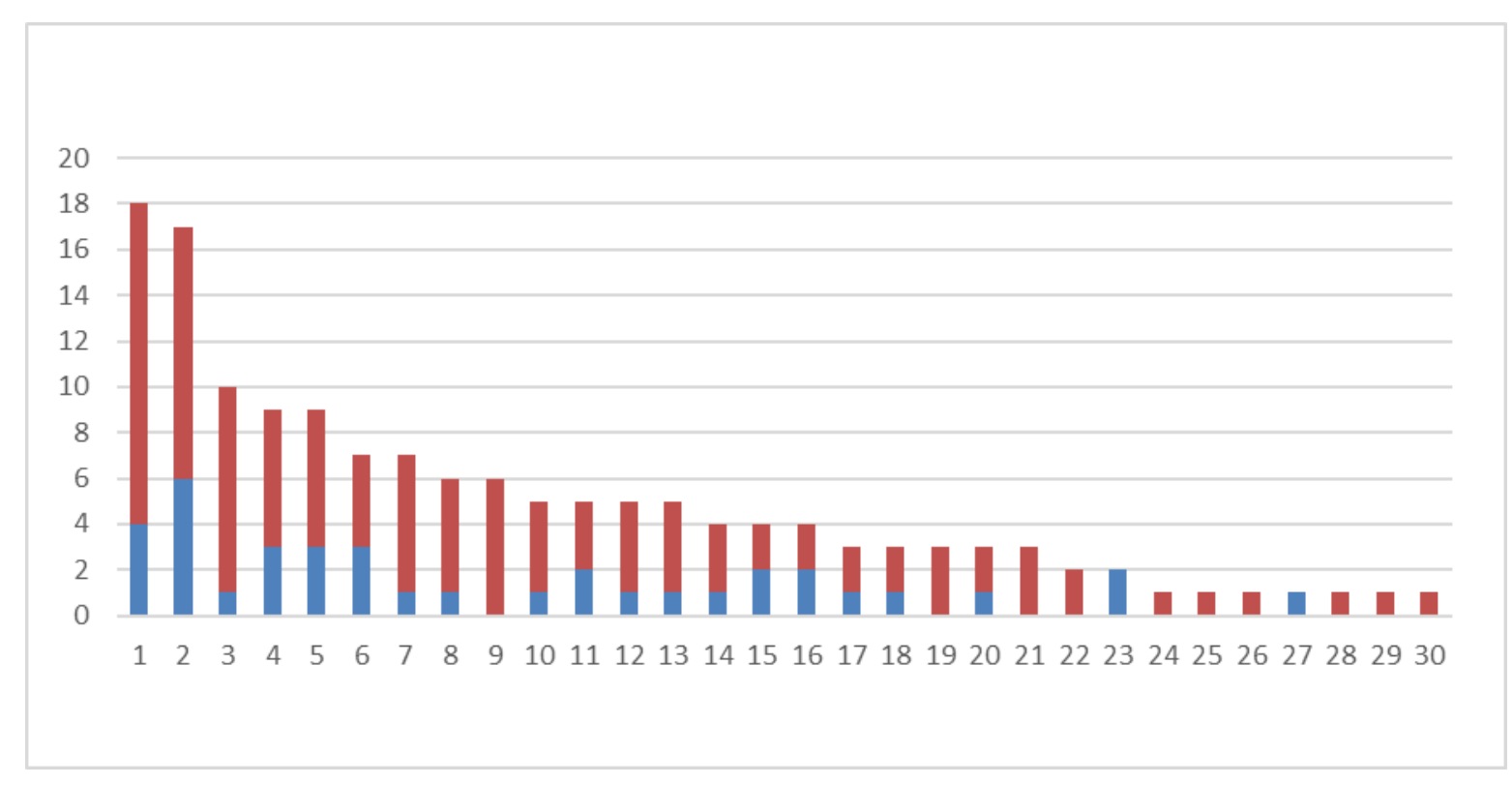

$=$ Single Disciplinary; $\square=$ Home Disciplinary

Notes:

- $\quad$ The colors indicate the mentioned key

- $\quad$ The vertical axis denotes the number of times the respective IS sub-discipline occurs in the papers with the Single and Home Disciplinary Contributions

\begin{tabular}{|l|l|l|l|l|}
\hline 1: IS Use & $\begin{array}{l}\text { 7: Systems } \\
\text { analysis and } \\
\text { design }\end{array}$ & $\begin{array}{l}\text { 13: Knowledge } \\
\text { management }\end{array}$ & 19: IS affordances & $\begin{array}{l}\text { 25: Digital } \\
\text { business models }\end{array}$ \\
\hline 2: E-Commerce & $\begin{array}{l}\text { 8: IS } \\
\text { implementation }\end{array}$ & $\begin{array}{l}\text { 14: Online social } \\
\text { networks }\end{array}$ & 20: IS alignment & 26: E-government \\
\hline 3: Outsourcing & 9: IS strategy & 15: Open source & 21: IS innovation & 27: Privacy \\
\hline 4: IS acceptance & $\begin{array}{l}\text { 10: Business } \\
\text { value of IT }\end{array}$ & $\begin{array}{l}\text { 16: Project } \\
\text { management }\end{array}$ & $\begin{array}{l}\text { 22: Control \& } \\
\text { audit }\end{array}$ & 28: IS dark side \\
\hline 5: IS adoption & 11: IS capability & $\begin{array}{l}\text { 17: Digital } \\
\text { products \& } \\
\text { services }\end{array}$ & $\begin{array}{l}\text { 23: Online } \\
\text { communities }\end{array}$ & 29: Virtual teams \\
\hline $\begin{array}{l}\text { 6: Software } \\
\text { development }\end{array}$ & 12: IS security & $\begin{array}{l}\text { 18: Healthcare } \\
\text { modelling }\end{array}$ & 30: Virtual worlds \\
\hline
\end{tabular}


Figure 3: Disciplines Most B orrowed from and Contributed to: Distribution of Disciplines in the Home and Cross Disciplinary Contributions

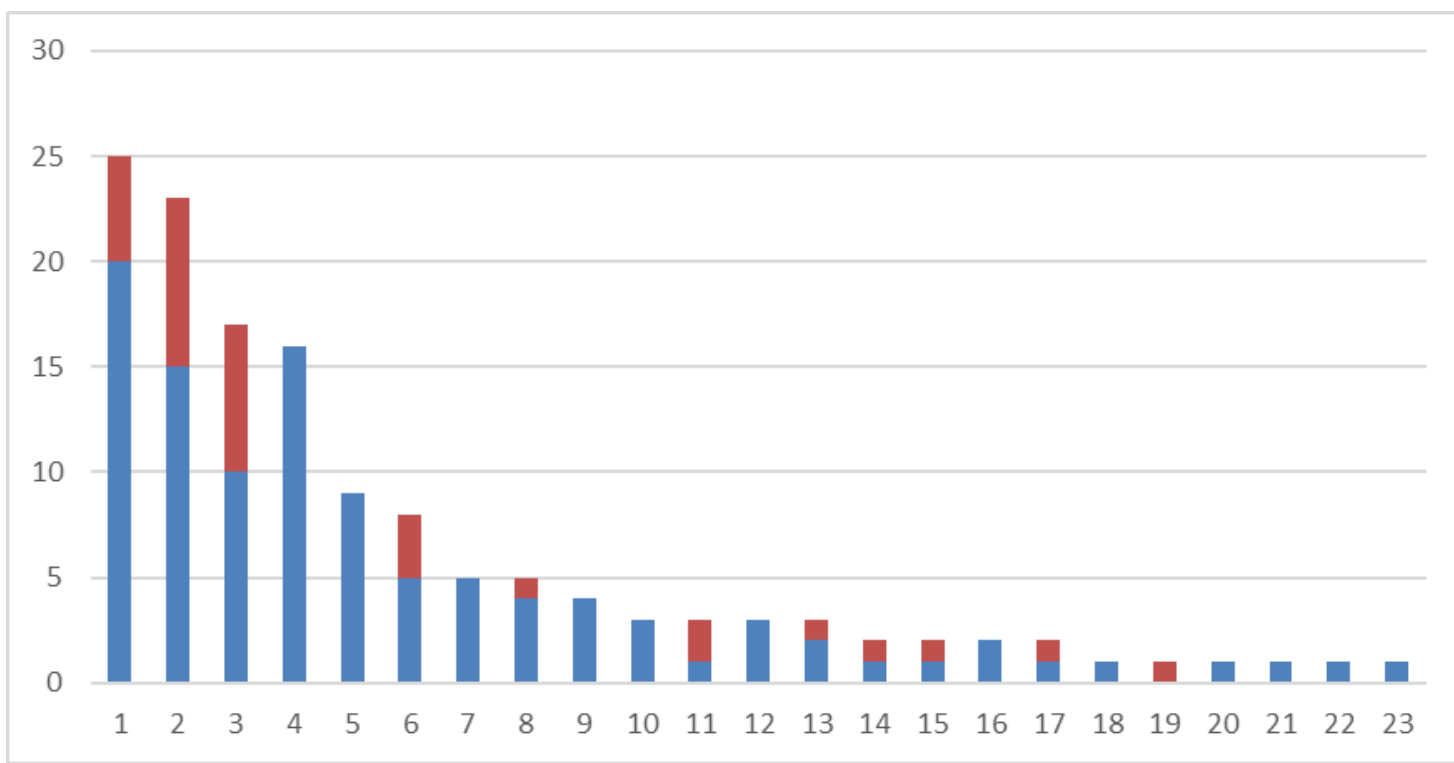

= Home Disciplinary (Disciplines most borrowed from ) $\square=$ Cross Disciplinary (Disciplines most contributed to

Notes:

- $\quad$ The colors indicate the mentioned key

- $\quad$ The vertical axis denotes the number of times the respective discipline occurs in the papers with the Home and Cross Disciplinary Contributions

\begin{tabular}{|l|l|l|l|}
\hline 1: Psychology & 7: Cognitive Science & $\begin{array}{l}\text { 13: Operations } \\
\text { Management }\end{array}$ & $\begin{array}{l}\text { 19: Computational } \\
\text { Biology }\end{array}$ \\
\hline 2: Strategy & $\begin{array}{l}\text { 8: General } \\
\text { Management }\end{array}$ & 14: Computer Science & 20: Healthcare \\
\hline $\begin{array}{l}\text { 3: Organizational } \\
\text { Behaviour }\end{array}$ & $\begin{array}{l}\text { 9: Technology } \\
\text { Management }\end{array}$ & 15: Finance & 21: Justice/Law \\
\hline 4: Economics & 10: Communications & 16: HCI & 22: Social Informatics \\
\hline 5: Operations Research & 11: Human Resources & 17: Neuroscience & 23: Signal Processing \\
\hline 6: Sociology & 12: Marketing & 18: Philosophy & \\
\hline
\end{tabular}


Figure 4: Information Systems as a Flexibly Stable Discipline

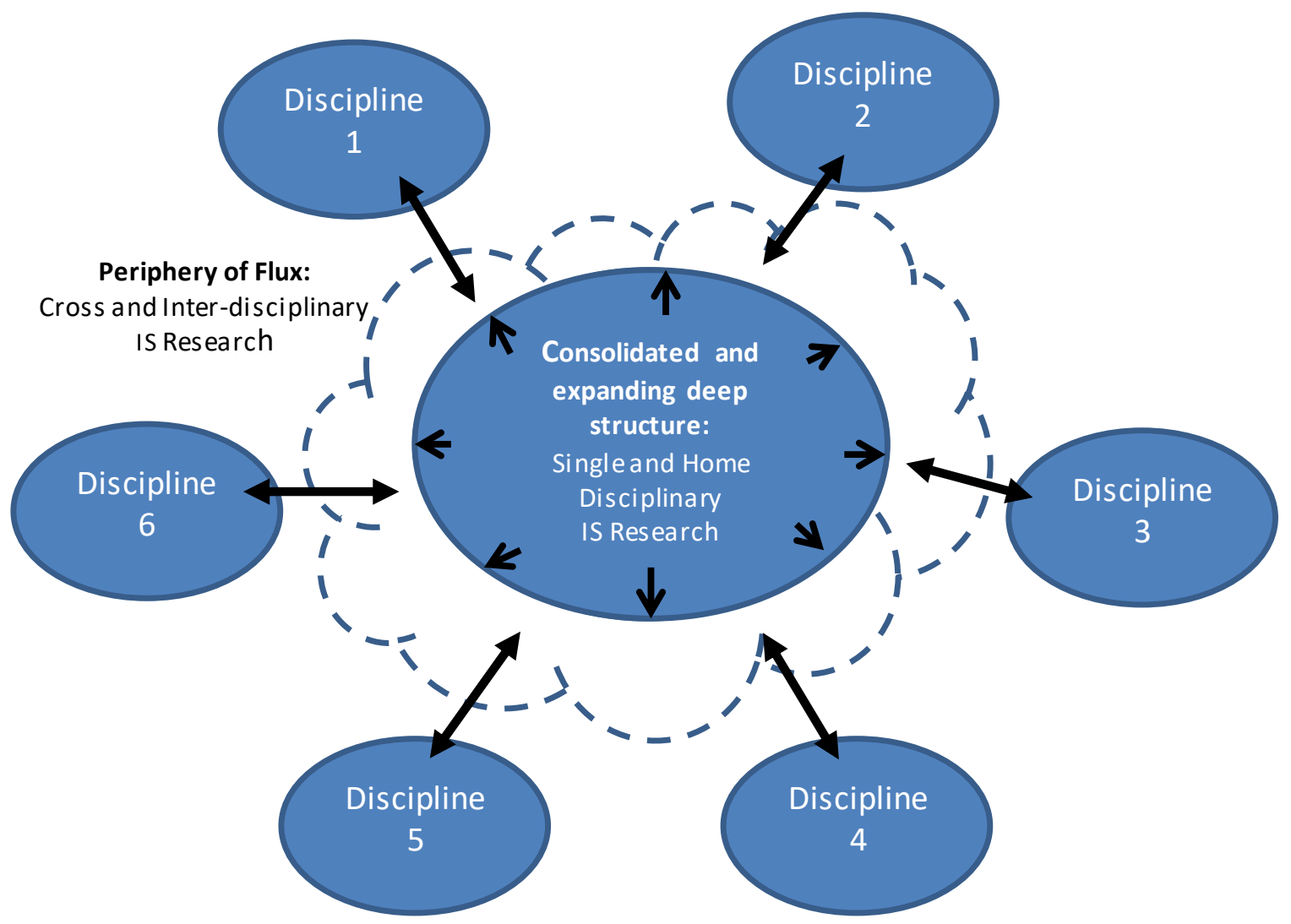


Table 1: Summary Description of Journals and Article Codes

\begin{tabular}{|l|c|c|c|c|c|c|c|}
\hline Journal & SD & HD & CD & ID & HD-ID & CD-ID & Total \\
\hline EJIS & 6 & 15 & 4 & 0 & 0 & 0 & 25 \\
\hline ISJ & 4 & 8 & 1 & 0 & 0 & 0 & 13 \\
\hline ISR & 9 & 23 & 3 & 0 & 0 & 0 & 35 \\
\hline JAIS & 3 & 11 & 4 & 0 & 0 & 2 & 20 \\
\hline JIT & 5 & 8 & 0 & 0 & 0 & 0 & 13 \\
\hline JMIS & 8 & 13 & 4 & 0 & 0 & 0 & 25 \\
\hline JSIS & 3 & 9 & 1 & 0 & 0 & 0 & 13 \\
\hline MISQ & 4 & 18 & 7 & 0 & 1 & 2 & 32 \\
\hline Total & 42 & 105 & 24 & 0 & 1 & 4 & 176 \\
\hline Total as \% & $\mathbf{2 4 \%}$ & $\mathbf{6 0 \%}$ & $\mathbf{1 3 \%}$ & $\mathbf{0 \%}$ & $\mathbf{1 \%}$ & $\mathbf{2 \%}$ & \\
\hline
\end{tabular}

Note: The codes were assigned according to the following logic:

SD: if it made a Single disciplinary contribution

HD: if it made a Home disciplinary contribution

CD: if it made a Cross disciplinary contribution

ID: if it if it made an inter-disciplinary contribution at the intersection of the IS discipline and one or more other disciplines

HD-ID: if it was coded as both HD and ID

CD-ID: if it was coded as both CD and ID 
Table 2: Single Disciplinary IS Research

\section{Objective: B uild a robust cumulative body of IS research that embodies the disciplinary} distinctiveness of IS.

Objectives achieved through

Investigating new IS topics and adding new IS sub-disciplines
Examples

New topics that relate to how IS can help address or create societal challenges such as, for instance, reduce corruption and increase transparency in governments, create technology addiction, and increase or reduce social power of marginalized societies. Tow et al. (2010) explain why users of social networking websites such as Facebook willingly post personal information because their objective is to communicate with family and friends and they are unaware of the risks involved. Such information disclosure behaviour makes possible phenomenon such as cyber stalking.

\footnotetext{
Applying and adapting existing IS concepts to explain new IS enabled phenomenon
} Conger et al. (2013) propose a theoretical framework for understanding information privacy in the context of , by drawing on existing IS concepts such as capabilities of emerging technologies and their use by corporate and illegal organizational entities. They build on prior research that examined personal information privacy as largely determined by the transaction between the customer and the provider of goods and services, to that determined by additional, third parties. These include other, legal data sharing partners and illegal entities that do not directly interact with the individual, but instead influence personal information privacy through their interaction with vendors and with each other. 
Table 3: Home Disciplinary IS Research

\section{Objective: Explain and analyse diverse, rich and complex IS-enabled phenomena by bringing to bear insights from appropriate refere nce disciplines.}

Objectives achieved through

Investigating new IS-enabled phenomenon
Examples

Feller et al (2012) contribute to the understanding of the emerging phenomenon of IS enabled crowdsourcing for innovation. They explain how organizations can obtain intellectual property from individuals and firms they have no prior relationship with. They draw from the concepts of innovation networks and brokerages to describe how innovation providers and innovators seekers can come together to easily and mutually transfer knowledge from a variety of sources, develop and innovation prioritize problems and solutions, and develop stable relationships over time.

Developing new contextualized Ravishankar et al. (2013) study an offshoring vendor in India explanations and understanding of through the anthropological lens of post-colonialism. They existing IS - enabled phenomenon. management strategies, vendors engage in impression management, in tackling power differentials with western clients, and in expressing agency. However, they do not develop customer intimacy/satisfaction as predicted by the literature. The paper applies post-colonialism concepts such as social power differential to the context of IT offshoring to India, a former British colony, and in doing so, reveals a newly understanding of an existing phenomenon, that of IT off-shoring. 
Table 4: Cross Disciplinary IS Research

Obje ctive: Theoretically contribute to other disciplines that study IS-enabled phenomena.

\begin{tabular}{|c|c|c|c|}
\hline $\begin{array}{l}\text { Objectives achieved } \\
\text { through }\end{array}$ & Examples & $\begin{array}{l}\text { Contribution } \\
\text { to IS }\end{array}$ & $\begin{array}{l}\text { Contribution to } \\
\text { Reference Discipline }\end{array}$ \\
\hline \multirow[t]{2}{*}{$\begin{array}{l}\text { Conceptualizing IS } \\
\text { constructs and their } \\
\text { relationships in ways } \\
\text { that theoretically relate } \\
\text { them to constructs and } \\
\text { relationships in other } \\
\text { disciplines }\end{array}$} & $\begin{array}{l}\text { Garfield and Dennis (2012), } \\
\text { examining group } \\
\text { development in the context of } \\
\text { virtual teams who interact } \\
\text { through the use of IS, show } \\
\text { that teams who use IS- } \\
\text { mediated communication } \\
\text { follow different processes of } \\
\text { group development than those } \\
\text { who do not. }\end{array}$ & $\begin{array}{l}\text { Shows how } \\
\text { IS-mediation } \\
\text { influences } \\
\text { the processes } \\
\text { of group } \\
\text { development. }\end{array}$ & $\begin{array}{l}\text { Psychology: Explains } \\
\text { how group dynamics in } \\
\text { teams depend on the } \\
\text { particular IS and how it } \\
\text { is used }\end{array}$ \\
\hline & $\begin{array}{l}\text { Young et al. (2012), drawing } \\
\text { on data from use of } \\
\text { knowledge management } \\
\text { systems in a Taiwanese } \\
\text { context, show that when the } \\
\text { system had the potential to } \\
\text { reveal both the identity and } \\
\text { the expertise of contributing } \\
\text { experts, it was not used from } \\
\text { a fear that the same experts } \\
\text { would lose 'face' if their } \\
\text { revealed expertise was found } \\
\text { lacking under everyone's } \\
\text { 'gaze' through the system. }\end{array}$ & $\begin{array}{l}\text { Reveals } \\
\text { reasons that } \\
\text { might } \\
\text { prevent } \\
\text { effective use } \\
\text { of the } \\
\text { knowledge } \\
\text { management } \\
\text { system. }\end{array}$ & $\begin{array}{l}\text { Psychology: Establishes } \\
\text { that 'face' could be } \\
\text { influenced or destroyed } \\
\text { by electronic systems, } \\
\text { thereby revealing a new } \\
\text { relationship between an } \\
\text { established concept, face, } \\
\text { and a new IS, knowledge } \\
\text { management systems. }\end{array}$ \\
\hline $\begin{array}{l}\text { Considering IS as a } \\
\text { reference discipline that } \\
\text { can theoretically inform } \\
\text { phenomena and } \\
\text { problems investigated } \\
\text { in other disciplines }\end{array}$ & $\begin{array}{l}\text { Kane et al. (2014) juxtapose } \\
\text { emerging platforms of IT- } \\
\text { enabled social networks with } \\
\text { an established typology of } \\
\text { social networks to reveal how } \\
\text { online and offline social } \\
\text { networks are theoretically } \\
\text { distinct. }\end{array}$ & $\begin{array}{l}\text { Explains the } \\
\text { nature of } \\
\text { social media } \\
\text { enabled } \\
\text { digital } \\
\text { networks. }\end{array}$ & $\begin{array}{l}\text { Sociology: Introduces } \\
\text { and describes a new type } \\
\text { of networks based on } \\
\text { social media, informed } \\
\text { by the theoretical } \\
\text { properties of online } \\
\text { networks; IS thus being } \\
\text { the reference discipline }\end{array}$ \\
\hline
\end{tabular}


Table 5: Inte rdisciplinary IS Research

\begin{tabular}{|c|c|c|}
\hline \multicolumn{3}{|c|}{$\begin{array}{l}\text { Objective: Create transformative theoretical concepts and relationships by integrating } \\
\text { theories and concepts from IS and other dis ciplines, through alternate ontological } \\
\text { formulations and interpre tation. }\end{array}$} \\
\hline $\begin{array}{l}\text { Objectives achieved } \\
\text { through: }\end{array}$ & Examples & Interdisciplinary Contribution \\
\hline \multirow[t]{2}{*}{$\begin{array}{l}\text { Revealing, describing } \\
\text { and explaining } \\
\text { ontologically new } \\
\text { concepts that } \\
\text { illustrate fusion or } \\
\text { integration of ideas } \\
\text { from multiple } \\
\text { disciplines }\end{array}$} & $\begin{array}{l}\text { Vaast et al. (2013) examine how new } \\
\text { actor categories with new identities } \\
\text { emerge in technology-mediated } \\
\text { discourses such as blogging. Fusing the } \\
\text { concepts of the social actor and use of IT } \\
\text { from the IS literature, and identity from } \\
\text { the sociology literature, the paper } \\
\text { conceptualizes an ongoing identity } \\
\text { formation process at the theoretical } \\
\text { intersection and integration of media use } \\
\text { practices, identity, and media } \\
\text { affordances }\end{array}$ & $\begin{array}{l}\text { Interdisciplinary Concept: Fluid } \\
\text { identity through an ongoing } \\
\text { process of identity formation. } \\
\text { Fused concepts: Social actor } \\
\text { and IT use (from IS), and } \\
\text { identity (from Sociology) }\end{array}$ \\
\hline & $\begin{array}{l}\text { Integrating the theoretical concepts of } \\
\text { collective mindfulness, IT appropriation, } \\
\text { technologies-in-practice, and dialectic } \\
\text { theory, Carlo et al. (2012) formulate the } \\
\text { fused concept of collective minding. }\end{array}$ & $\begin{array}{l}\text { Interdisciplinary Concept: } \\
\text { Collective minding as the } \\
\text { process through which users } \\
\text { appropriate IT in dialectic, dual } \\
\text { and collective ways to be } \\
\text { simultaneously both mindful } \\
\text { and mindless. Fused concepts: } \\
\text { IT appropriation, technologies- } \\
\text { in-practice (from IS), and } \\
\text { collective mindfulness (from } \\
\text { Psychology) }\end{array}$ \\
\hline $\begin{array}{l}\text { Integrating theories } \\
\text { from different } \\
\text { disciplines to solve an } \\
\text { IS conceptual } \\
\text { problem }\end{array}$ & $\begin{array}{l}\text { Strong et al. (2014) integrate the } \\
\text { theoretical concepts of affordances, the } \\
\text { materiality of IS, the situated nature of IS } \\
\text { use, and the intentionality of the IS user, } \\
\text { to develop new conceptual formulations } \\
\text { to explain organizational change from } \\
\text { implementation of EHR. }\end{array}$ & $\begin{array}{l}\text { Interdisciplinary Concepts: } \\
\text { 'actualization of an } \\
\text { affordance's potential' and } \\
\text { 'bundles of inter-related } \\
\text { affordances'. Fused concepts: } \\
\text { materiality of IS, situated use } \\
\text { (from IS), and affordances } \\
\text { (from Sociology) and user } \\
\text { intentionality (from } \\
\text { Psychology) }\end{array}$ \\
\hline
\end{tabular}




\section{Knowledge Contribution Guidance for Research Practice}

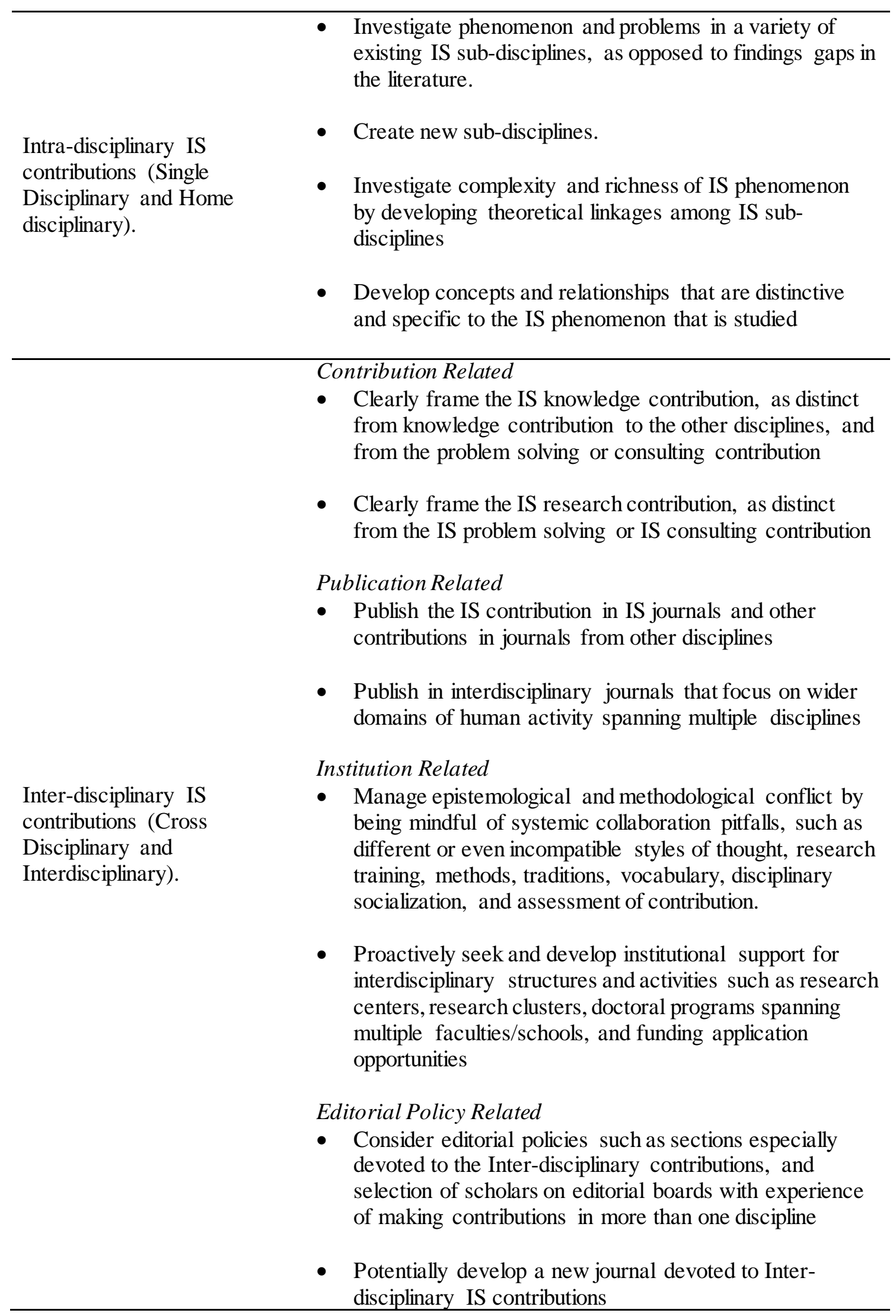




\section{APPENDICES}

Appendix Table 1: Articles Published By and Selected From Eight Journals

\begin{tabular}{cccc}
$\begin{array}{c}\text { Journal } \\
\text { Name }\end{array}$ & $\begin{array}{c}\text { Number and percentage of } \\
\text { articles published in 2010- } \\
2014 \text { (Total of 1407 broken } \\
\text { down by journal) }\end{array}$ & $\begin{array}{c}\text { Number of articles selected } \\
\text { for our analysis (every } 8^{\text {th }} \\
\text { article published for each } \\
\text { journal was selected for a } \\
\text { total of 176) }\end{array}$ & $\begin{array}{c}\% \text { of the total of 176 } \\
\text { articles for each } \\
\text { journal }\end{array}$ \\
\hline EJIS & $197(14 \%)$ & 25 & $14.2 \%$ \\
ISJ & $106(7.5 \%)$ & 13 & $7.4 \%$ \\
ISR & $280(19.9 \%)$ & 35 & $19.9 \%$ \\
JAIS & $157(11.2 \%)$ & 20 & $11.4 \%$ \\
JIT & $106(7.5 \%)$ & 13 & $7.4 \%$ \\
JMIS & $199(14.1 \%)$ & 25 & $14.2 \%$ \\
JSIS & $106(7.5 \%)$ & 13 & $7.4 \%$ \\
MISQ & $256(18.2 \%)$ & 32 & $18.2 \%$ \\
\hline
\end{tabular}


Appendix Table 2: Discipline Codes (Management disciplines from the ABS list are in italics)

\begin{tabular}{|c|c|c|c|}
\hline Code & IS Sub-disciplines & Code & Non-IS Disciplines \\
\hline 1.01 & Business Process Management & 2 & Accounting \\
\hline 1.02 & Business Value of IT & 3 & Cognitive Science \\
\hline 1.03 & Control/Audit & 4 & Communication \\
\hline 1.04 & Data modeling & 5 & Computer Science \\
\hline 1.05 & Digital Business Models & 6 & Computational Biology \\
\hline 1.06 & $\begin{array}{l}\text { Digital Products \& Services (including music } \\
\text { etc.) }\end{array}$ & 7 & Economics \\
\hline 1.07 & $\begin{array}{l}\text { E-Commerce (including online advertising, } \\
\text { mobile apps, etc.) }\end{array}$ & 8 & Finance \\
\hline 1.08 & E-Government & 9 & General Management \\
\hline 1.09 & $\begin{array}{l}\text { Healthcare IS (including eHealth and } \\
\text { Telemedicine) }\end{array}$ & 10 & Healthcare \\
\hline 1.10 & Information/Data Privacy & 11 & Human Computer Interaction \\
\hline 1.11 & IS acceptance & 12 & Human Resource Management \\
\hline 1.12 & IS adoption & 13 & Justice/Law \\
\hline 1.13 & IS affordances & 14 & Marketing \\
\hline 1.14 & IS alignment & 15 & NeuroScience \\
\hline 1.15 & IS appropriation & 16 & Operations Management \\
\hline 1.16 & IS avoidance & 17 & Organizational Behavior \\
\hline 1.17 & IS capability & 18 & Operations Research \\
\hline 1.18 & IS dark side (e.g. technostress) & 19 & Philosophy \\
\hline 1.19 & IS human resource & 20 & Psychology \\
\hline 1.20 & IS implementation & 21 & Social Informatics \\
\hline 1.21 & IS innovation & 22 & Sociology \\
\hline 1.22 & IS resistance & 23 & Strategy \\
\hline 1.23 & IS security & 24 & Technology Management \\
\hline 1.24 & IS strategy & 25 & Signal Processing \\
\hline 1.25 & $\begin{array}{l}\text { IS use (includes use of various kinds of } \\
\text { systems) }\end{array}$ & & \\
\hline 1.26 & Knowledge management & & \\
\hline 1.27 & Online communities & & \\
\hline 1.28 & Online social networks & & \\
\hline 1.29 & Open source software development & & \\
\hline 1.30 & Outsourcing/Offshoring & & \\
\hline 1.31 & Project management & & \\
\hline 1.32 & Service Oriented Architecture & & \\
\hline 1.33 & \begin{tabular}{|l|}
$\begin{array}{l}\text { Software development (including algorithm } \\
\text { development) }\end{array}$ \\
\end{tabular} & & \\
\hline 1.34 & Software industry & & \\
\hline 1.35 & Standards & & \\
\hline 1.36 & System Analysis and Design & & \\
\hline 1.37 & Virtual teams & & \\
\hline 1.38 & Virtual worlds & & \\
\hline
\end{tabular}




\begin{tabular}{|c|c|c|c|c|c|c|c|c|c|}
\hline $\begin{array}{c}\text { Paper } \\
\text { Identifier }\end{array}$ & $\begin{array}{c}\text { Citation } \\
\text { Information }\end{array}$ & Disciplines & D1 code & D2 code & SD & HD & CD & ID & $\begin{array}{c}\text { Paper } \\
\text { Classifi- } \\
\text { cation }\end{array}$ \\
\hline JAIS 8 & Sun (2010) & $\begin{array}{c}\text { D1: IS Use } \\
\text { D2: Psychology }\end{array}$ & 1.25 & 20 & No & $\begin{array}{c}\text { Yes } \\
\text { IS Use }(1.25)\end{array}$ & No & No & $\mathrm{HD}$ \\
\hline JAIS 152 & $\begin{array}{l}\text { Schlagwein and } \\
\text { Bjorn-Andersen, } \\
\text { 2014) }\end{array}$ & $\begin{array}{c}\text { D1: IS Innovation } \\
\text { D2: OB }\end{array}$ & 1.21 & 17 & No & $\begin{array}{c}\text { No } \\
\text { IS Innovation } \\
(1.21)\end{array}$ & $\begin{array}{c}\text { Yes } \\
\text { OB (17) }\end{array}$ & No & $\mathrm{CD}$ \\
\hline EJIS 8 & Kreps (2010) & $\begin{array}{c}\text { D1: IS Use } \\
\text { D2: Philosophy }\end{array}$ & 1.25 & 19 & No & $\begin{array}{c}\text { Yes } \\
\text { IS Use }(1.25)\end{array}$ & No & No & $\mathrm{HD}$ \\
\hline JSIS 48 & $\begin{array}{l}\text { Dhillon et al. } \\
\qquad(2011)\end{array}$ & $\begin{array}{c}\text { D1: IS } \\
\text { Implementation } \\
\text { D2: OB }\end{array}$ & 1.20 & 17 & No & $\begin{array}{c}\text { No } \\
\text { IS } \\
\text { Implementation } \\
(1.20) \\
\end{array}$ & $\begin{array}{c}\text { Yes } \\
\text { OB (17) }\end{array}$ & No & $\mathrm{CD}$ \\
\hline MISQ 192 & Vaast (2013) & $\begin{array}{c}\text { D1: IS Use } \\
\text { D2: Sociology }\end{array}$ & 1.25 & 22 & No & $\begin{array}{c}\text { No } \\
\text { IS Use }(1.25)\end{array}$ & $\begin{array}{c}\text { Yes } \\
\text { Sociology } \\
(22)\end{array}$ & $\begin{array}{c}\text { Yes } \\
\text { IS Use (1.25) } \\
\text { Sociology (22) }\end{array}$ & CD-ID \\
\hline JMIS 192 & $\begin{array}{l}\text { Barua and Mani } \\
\qquad(2014)\end{array}$ & $\begin{array}{c}\text { D1: IS } \\
\text { Outsourcing } \\
\text { D2 Strategy }\end{array}$ & 1.30 & 23 & No & $\begin{array}{c}\text { Yes } \\
\text { IS Outsourcing } \\
(1.30) \\
\end{array}$ & No & No & $\mathrm{HD}$ \\
\hline ISR 16 & $\begin{array}{c}\text { Tiwana and } \\
\text { Konsynski } \\
(2010)\end{array}$ & D1: IS Alignment & 1.14 & & $\begin{array}{c}\text { Yes } \\
\text { IS Alignment } \\
(1.13) \\
\end{array}$ & No & No & No & SD \\
\hline ISJ 80 & $\begin{array}{l}\text { Conger et al. } \\
\text { (2013) }\end{array}$ & $\begin{array}{l}\text { D1: Information } \\
\text { Privacy }\end{array}$ & 1.10 & & $\begin{array}{c}\text { Yes } \\
\text { Information } \\
\text { Privacy (1.09) } \\
\end{array}$ & No & No & No & SD \\
\hline
\end{tabular}

